\title{
Are the Negative Mental Health Effects of Gender Discrimination (GD) Salient across Cultures? Does Self-Esteem Mediate These Effects: GD as a Continuous Traumatic Stress and the Pathways to Its Negative Dynamics?
}

\author{
Ibrahim A. Kira1, Andrea Z. Omidy², Mounir Fawzi³, Kenneth G. Rice4, Mohab Fawzi³, \\ Linda Lewandowski ${ }^{5}$, Mireille Bujold-Bugeaud1 \\ ${ }^{1}$ Center for Cumulative Trauma Studies, Stone Mountain, GA, USA \\ ${ }^{2}$ Boston Medical Center, Boston, MA, USA \\ ${ }^{3}$ Zaqaziq University, Zaqaziq, Egypt \\ ${ }^{4}$ Georgia State University, Atlanta, GA, USA \\ ${ }^{5}$ University of Massachusetts, Amherst, MA, USA \\ Email: kiraaref@aol.com
}

Received 31 December 2014; accepted 18 January 2015; published 23 January 2015

Copyright (C) 2015 by authors and Scientific Research Publishing Inc.

This work is licensed under the Creative Commons Attribution International License (CC BY). http://creativecommons.org/licenses/by/4.0/

(c) (i) Open Access

\section{Abstract}

Traumatology perspective on gender discrimination GD, views it as type III identity continuous trauma that has continuous and stable negative mental health effects. Current work evaluated the salience of GD's negative effects across different cultures and outcome measures and tested the differential impact of GD within the household (GD-P), and GD within social institutions (GD-S). Data from four previous studies on American Indians, Palestinians, and clients of mental health clinics in Egypt and torture survivors in the US were re-analyzed. All the four studies used the same measure of GD, and trauma types, with similar and different outcome measures which allowed measuring the stability of the effects across different cultures and different outcome measures. Partial correlation and path analysis were conducted. GD predicted increased PTSD, cumulative trauma disorders, general anxiety, annihilation anxiety, and decreased in self-esteem, general assessed functioning. Results suggested that linear and non-linear effects of GD supported its cumulative dynamics. GD-S was associated with more negative outcomes than GD-P. Further, internalizing and appraising GD as positive mediated by resulted decrease in self-esteem, predicted negative mental health outcomes, while negative appraisal did not predict any negative change. Positive appraisal of GD may be a negative coping strategy. The implications of results for trauma 
theory, counseling and social justice, and for future research were discussed.

\title{
Keywords
}

\author{
Gender Discrimination, Appraisal, Coping, Type III Chronic traumas, Developmentally-Based \\ Trauma Framework (DBTF)
}

\section{Introduction}

While gender differences are normative and positive for both interdependent genders (Wood \& Eagley, 2003), gender discrimination against females is not normative and is culturally constructed. Gender discrimination (GD) is not a natural fact that is simply derived from biological and sex differences. It is rather a complex social, historical, and cultural phenomenon that regulates, in critical way, social life and social institutions around male's dominance and female's subjugation. It includes negative attitudes, beliefs, and behaviors that devalue, denigrate, stigmatize, or restrict females. Gender discrimination (GD) (by family and/ or by social institutions and cultures) is chronic identity trauma that includes prejudice and unfair disadvantageous treatment and/ or negative perception based on a person's female gender. It includes the differential disparity in status, power and prestige and may include the belief that a male is intrinsically superior, especially in the case of oppression of women by men. GD usually inflates the dominant gender and deflates the subjugated gender identity and selfworth (esteem and efficacy), potentially hurting both genders. Research suggested that gender discrimination is a risk factor for females and protective factor, and can potentially be a risk factor as well, for males (Kira et al., 2012a). It was found that GD contributes to lower self-esteem, and associated higher internalizing disorders in females and, higher empowerment, or inflated self-esteem and associated with higher risk-taking behaviors and externalizing disorders (and authoritarianism) in males (Kira et al., 2012a; Rosenfield, Lennon, \& White, 2005; Kaufman, 2009). Gender discrimination as identity type III trauma, for females is a systemic social-structural inter-gender trauma, comprises micro (e.g., insults and exclusions) as well as macro aggressions (e.g., genderbased violence, trafficking). Macro-aggressions terrorize and increase the targeted individual's sensitivity to micro-aggressions that can be proxies for the anticipated macro aggressions and can be re-traumatizing and reterrorizing for the victims. Gender discrimination is based, in such cultures, on an organizing principle and an immutable fact of men's superiority and dominance over women on familial, social, political, religious and economic institutions. Even systems of knowledge and dominant cognitions reflect mostly men's gendered views of the natural and social world and their production of gendered knowledge. The severity of Gender inequality varies tremendously across cultures and sub-cultures., and is usually higher within conservative cultures (e.g., Daly \& Chesney Lind, 1988). Feminist theorists (e.g., Enns, 2004; Kira et al., 2012) propose that traditional gender role socialization and experiences of external and internalized oppression negatively impacts the mental health and wellbeing of both genders. Several liberal, cultural, and radical feminist theories have been influential in articulating the various ways rigid gender role socialization and gender stereotypes promote devaluation of women, systemically enhances patriarchy, male domination and control over of women (Enns, 2004; Jaggar \& Rothenberg, 1993; Worell \& Remer, 2003).

Kira and associates developed a developmentally-based trauma framework (DBTF) (e.g., Kira, 2001, 2004, 2010; Kira et al., 2008, Kira, Fawzi, \& Fawzi, 2013), that theorized gender discrimination as identity type III trauma, for females (Kira et al., 2010, Kira, Ashby, Lewandowski, Smith, \& Odenat, 2012). A type III trauma is one that is chronic and on-going and may not stop (contrasted with Type I trauma (a single event or blow) and type II trauma which is a set of psychological sequelae that happened in the past and stopped). Type III has potential of accumulation and proliferation dynamics and is potentially the most severe (Kira, Ashby, Lewandowski et al., 2013). GD, as independent trauma can proliferate to different related or dependent traumas, such as, gender-based violence, intimate violence, stalking, and sex trafficking which is some of the GD social products. Sex trafficking, for example, was found to have primary and secondary severe negative mental health effects on females and on communities (Rafferty, 2008). Because such chronic traumas represent the current state of social structures and is related to their dominant powers, it tends to be obscured, ignored, minimized, or denied as trauma, even it has potentially the worst impact as it is continuous, life long, and do no stop. Categories and 
demographics have been used, in research, as proxies to such inequalities, discriminations and social structural violence, instead of measuring its impact. The demographic variable "gender", used in research, is mostly a proxy of such poorly articulated GD (in addition to potential normative differences) that exists and varies across cultures. We propose that most of differences found in research using the demographic variable "gender" are due, at least in great part, to the GD's stress and trauma dynamics.

GD as a serious continuous life-trauma for females, does not only make them more vulnerable, but also has the potential of yielding or exasperating symptoms of PTSD, depression, complex PTSD and other post-trauma spectrum disorders as well as cumulative mental and physical health disorders' comorbidity. GD was found, using mostly western samples, to be associated with physical and psychiatric disorders (Kira et al., 2010; Landrine, Klonoff, Gibbs, Manning, \& Lund, 1995). One of the significant GD related disorders are eating disorders. Internalization of the pervasive male-centered norms of women's objectification may minimize their competence, and deny them their agented qualities and negatively affect their performance (Quinn, Kallen, Twenge, \& Fredrickson, 2006) and is related to increasing high rate of eating disorders amongst females (compared to males). Such disorders may develop to comply with such norms set by male dominated culture (e.g., Ferreiro, Seoane, \& Senra, 2011). GD has been shown to negatively impact the mental health of both genders in torture survivors from over 20 countries (Kira et al., 2010, 2012a). Additionally, DBTF posits that GD intersects with other kinds of identity traumas, (e.g., discrimination and oppression) (Shields, 2008). The effects of Interlocking systems of oppression on females' life move beyond the added experiences of each. DBTF proposes that gender oppression is amplified by such intersections and interactions and their linear and non-linear cumulative dynamics (Kira, Alawneh, Aboumediene, Lewandowski, \& Laddis, 2014). Experimental and longitudinal data have shown strong evidence for the negative effect of perceived discrimination on well-being (Correa-Velez, Gifford, \& Barnett, 2010; Schmitt, Branscombe, \& Postmes, 2003). They have consistently documented the negative associations of different discriminations with health and quality of life across minority groups (for meta-analysis see: Pascoe \& Richman, 2009).

One of the characteristics of such chronic type III traumas is its linear and non-linear cumulative negative effects. While dose-response model (the parallel increase in effects caused by increased levels of exposure) describes linear traumatogenic dynamics (e.g., Altshuler, 1981), cumulative trauma model proposes different additional cumulative non-linear dynamics inherent in the threshold model (where a threshold value at which the behavior varies significantly) (Kira, 2010, Kira et al., 2006). Resilient female may have her breaking point with reactivation spreading of old and new traumatic stressors at which it could turn her to "snap" into a psychiatric casualty (for example, decompensation or suicide) or criminal acting out. Such non-linear dynamics of cumulative trauma are especially present in multiply traumatized victims of chronic traumas, such as GD (Kira, Ashby et al., 2012; Kira, Amer, \& Wroble, 2014).

There are two primary distinct but intersected Cultural channels that may transmit andpropagate GD traumatization dynamics: social institutions and family. Social, religious and social institutions may perpetrate GD systemic betrayal trauma (GD-S). Parents, family members and significant others (intra-household members) may perpetrate GD (family betrayal Trauma) (GD-P). Attitudes, beliefs and practices from social institutions and the public that serve to exclude women are often deeply entrenched in cultural, social and religious norms with different intensities (Freyd, DePrince, \& Gleaves, 2007; Kira, Lewandowski, Chiodo, \& Ibrahim, 2014). These gendered institutions have pivotal influence on people's professional and economic trajectories. There are many types of institutional and systemic gender discrimination and can range from workplace discrimination to violent hate crimes against women.

On the one hand, social support from family and significant others, as opposed to betrayal and discrimination has been shown to be related to self-esteem and coping; highlighting the ways in which one's family and significant others may help or hinder females as they cope with discrimination with society and other life adversities (Ayers, 2009). Parental gender preference of males over females is prevalent in most developing and even in some developed cultures (Hank, 2007). A preference for a son is one of the oldest issues in many cultures; in these cultures sons are also given preferential treatment over daughters (Das Gupta et al., 2003; Shah, 2005). An example of such extreme family-based discrimination, that has been institutionalized as well, is the law of primogeniture (the right of the firstborn male to inherit the entire estate, to the exclusion of older females or younger siblings) that was still enforced in some European countries till recently. Discrimination can even begin in the womb; there is evidence of pre-natal selective investments (Bharadwaj \& Nelson, 2012). Parental genderbased interactions can influence educational and professional outcomes differently for girls and boys. 
Gender Discrimination by parents, family members and significant others (GD-P) can have similar or different impact compared to gender discrimination by social and political institutions (GD-S). The outcome may be dependent on the severity of each and on the age of exposure. (For example adolescents may be more dependent on family and significant others and thus more affected by GD-P, while adults are more affected by GD-S). The differential physical and mental health effects of these two types of gender discrimination (GD-P and GD-S) are understudied. There is a need to explore the differential impact of each in each group and their stability crossculturally. Current study will explore such differences or similarities across specific cultural groups.

Further, there are powerful pressures from dominant gender actors who have a vested interest in maintaining a discriminatory status quo to minimize or disregard the presence of GD (e.g., Garcia, Schmitt, Branscombe, \& Ellemers, 2010; Kaiser, 2007). Even some members of the same disadvantaged group, to cope with distress related to GD, disapprove an individual who claims or emphasizes GD (Garcia et al., 2010). Indeed many females especially in traditional cultures deny experiencing discrimination even in the face of objective indicators to the contrary (Crosby, 1984). A motivation to justify the unjust GD may lead individuals to endorse explanations that portray gender differences as stemming from deep, essential cause (Brescoll, Uhlmann, \& Newman, 2013). System justification theory suggests that people have an essential motive to view their social system as just, fair, and good and will engage in different conscious or unconscious strategies to justify the status quo (Jost, Banaji, \& Nosek, 2004; Sidanius \& Pratto, 1999, Yeung, Kay, \& Peach, 2014). Justification of the status quo is sustained by motivated reasoning (Kay et al., 2009; Kunda, 1990), such as positive appraisal of GD. Appraisal strategies, for females, according to the DTBF framework are developed, at least in part, in an attempt to cope with the continuous distress of GD. Coping with GD continuous traumatic stress can arise through the internalization and acceptance of the self in a second-class status (or give up) to reduce distress, or through resistance. Acceptance coping may result in lowered self-esteem and submission to dominance. Positive appraisal of gender discrimination indicates mostly the acceptance and internalization of the female as having lower status as part of the established social order. Negative appraisal occurs through resistance of gender discrimination, at varying levels of intensity, for example through feminine ideology (Foster, 2009). While positive cognitive appraisal, in non-oppressive conditions, yield positive emotions and is usually associated with positive outcome and considered a positive coping (e.g., Kira et al., 2011-a; Scherer, Shorr, \& Johnstone, 2001), the opposite may be true in the case of oppression (e.g., Brondolo et al., 2006; Krieger, 1999). The typically positive relationship between positive appraisal and effective psychological functioning may be nullified within the context of oppression in some minority groups who positively appraised discrimination (Perez \& Soto, 2011; Soto et al., 2012). Matheson, Skomorovsky, Fiocco and Anisman (2007) found in a study of psychologically or physically abused women, that coping strategies that might appear beneficial, when considered in the broader context may actually undermine well-being. They suggest that in some contexts, reduced distress might limit active efforts to alter a dysfunctional situation. Internalized oppression found to be correlated with higher psychological distress in the affected gender (e.g., Szymanski \& Gupta, 2009).

However, each form of appraisal has its costs. Positive appraisal, leading to its acceptance, results in lowered self-esteem, lowered self-efficacy, and a relative loss of control. Negative appraisal, leading to resistance, can also have costs as women who succeed at male gender-typed tasks are frequently penalized for success (Heilman \& Okimoto, 2007). The dynamics of appraisal in the cases of internalizing or resisting GD, and its relationship with self-esteem, have never been empirically studied. Current study, will examine such dynamics in one of such cultures with high GD.

As, we discussed earlier, the severity of GD varies tremendously across cultures, world regions and countries. GD can be more severe especially in some traditional patriarchal hierarchical cultures and among the repressed groups (e.g., American Indians, Palestinians, refugees and torture survivors). Studies of GD around the world found that Southeast Asia and Latin America, with relatively the least GD, and Sub-Saharan Africa, the Indian Subcontinent and the Middle East/North Africa (MENA) region with relatively the highest GD

(http://www.genderindex.org/countries). According to the gender inequality index developed by United nations Human development Program (UNDP, 2013), Norway, followed by Australia and United States is the highest in gender equality within 186 ranked nations, Palestinian occupied territories ranked 110, Egypt ranked 112, Iraq ranked 131, Bhutan ranked 140, Myanmar ranked 149, and Nepal ranked 157 (these countries will be represented in current study samples).

In Egypt as elsewhere in MENA region, wife beating is related to various negative health outcomes. Study of domestic violence in Egypt found that thirty-four percent of women in the sample were ever beaten by their 
current husband while 16\% were beaten in the past year (Diop-Sidibéa, Campbellb, \& Beckerc, 2006). Women in Egypt are often subject to violence not only from family and community members, but also by agents of the state, including the police supposedly tasked with the protection of all citizens. In addition, women are constantly subjected to violence in the form of sexual harassment and abuse on the street, and approximately ninetyseven percent of Egyptian women are the victims of female genital mutilation (Diop-Sidibéa, Campbellb, \& Beckerc, 2006).

Violence against Palestinian women and girls is a multifaceted issue with significant association between political violence and increased domestic violence (Al Krenawi, Graham, \& Sehwail, 2007). Women and girls who speak out are often blamed for the violence inflicted upon them and their families are shamed for not exerting greater control over their sexuality. The 2006 Palestinian Central Bureau for Statistics (PCBS) survey revealed that $61.7 \%$ of ever-married women were exposed to psychological violence; $23.3 \%$ exposed to physical violence, and $10.9 \%$ exposed to sexual violence at least once during the year. While one-third of women believed that there was no excuse for a man to beat his wife, a substantial percentage still justified wife beating under several conditions. These beliefs were attributed to an adherence to an internalized patriarchal ideology (Haj-Yahia, 1998).

Native American women suffer violent crime at a rate three and a half times greater than the national average in the USA. National researchers estimate that this number is actually much higher than has been captured by statistics; according to the Department of Justice over $70 \%$ of sexual assaults are never reported (e.g., Bachman, Zaykowski, Kallmyer, Poteyeva, \& Lanier, 2008).

Refugees and torture survivors women, who do not enjoy the protection of their own governments, are among those most vulnerable to acts of violence, including sexual and gender-based violence (Kira et al., 2012). Gender-based violence (GBV) is most prevalent in environments where there is a general lack of respect for human rights. GBV occurs in most societies irrespective of culture, socioeconomic status or religion. Nevertheless, it has been identified that immigrant and refugee women are particularly at risk (Walter, 2001; Narayan, 1997). Krug et al. (2002) proposed that gender-based violence is usually at its highest point when communities and gender roles are in transition such is the case in refugees. GBV occurs during conflict, prior to flight, during flight, and in the country of asylum.

The current study aims at filling some of the gaps in the literature on GD. Specifically it evaluates the salience of the negative impact of GD on physical and mental health across different cultures (American Indians, Palestinians, Egyptians, and refugee torture survivors) and different measurement strategies, and test the traumatology perspective that emphasizes GD, as type III chronic identity trauma that may yield PTSD, Complex PTSD, eating disorders, and mental health comorbidities and reduced level of functioning . It explores the differential mental health impact of GD-P and GD-S across different cultures and measurement strategies. The study also examines, cross-culturally the effects of two different appraisal coping strategies, one by potentially internalizing (positive appraisal) and one by potentially resisting (negative appraisal) of gender discrimination and examine the dynamics of these effects in one of the samples.

The authors reanalyze material from four data sets in four prior studies in Egypt, Palestine, and the USA. All of the studies used the same comprehensive measure of cumulative stress that was developed based in the DBTF framework, the Cumulative Trauma Scale (Kira et al., 2008). This scale included a two-item sub-scale for measuring GD, GD-S and GD-P, and measured appraisal of each type (negative and positive appraisals). Each study collected community samples data (two community-based samples and two community clinics-based samples). The first study utilized a sample of American Indians (AI) living in the United States (Omidy, 2012; Kira, Omidy, \& Ashby, 2014). The second study conducted on a sample of Palestinians living in Gaza (e.g., Kira et al., 2011, 2013; Kira, Omidy, \& Ashby, 2014). The third study consisted of clients from a mental health clinic in Egypt (Kira, Fawzi, \& Fawzi, 2012b). The fourth study consisted of clients from a torture survivor's clinic in the United States, with representation from 32 countries (Kira et al., 2010, 2012). While all the four samples used the same Cumulative Trauma Scale that included a subscale of GD, there were variations in outcome measures specific to each study. However, three of the studies used the same measure of PTSD. The outcome measures will be used to explore the effects of GD across various assessment strategies of health and mental health.

\section{Hypotheses}

Hypothesis 1: Confirming the DBTF paradigm on GD as a chronic identity trauma, and replicating previous studies on Western samples, gender discrimination will be consistently (across the different cultural groups) asso- 
ciated (linearly and non-linearly) with negative mental health, negative physical health, lowered self-esteem and lowered global assessment of functioning (GAF)after controlling for demographics. Specifically, for mental and physical health, it will:

1) Be associated with binge eating, lower physical and social functioning, lower general mental health, and perceived general health, as well as with psychiatric comorbidities, illegal drug use and substance abuse in American Indians;

2) Be associated with post-traumatic stress disorder (PTSD), cumulative trauma disorders (CTD) (complex PTSD) in torture clients;

3) Be associated with depression, anxiety, annihilation anxiety, and lower self-reported health in Palestinian participants;

4) Be associated with PTSD, depression, anxiety, and psychiatric co-morbidities in Egyptian mental Health Clients.

Hypothesis 2: Gender discrimination, as a type III systemic chronic (life-time) identity trauma that intersects with similar traumas according to DBTF, will be associated with identity salience, other collective identity traumas, with personal identity traumas (that include sexual abuse, incest, and rape and domestic violence), betrayal or attachment, survival and secondary traumas. Further, because GD inhibits female achievement and self-efficacy, GD will be associated with achievement (self-actualization or role identity trauma).

Hypothesis 3: GD-P and GD-S will predict different levels of negative effects that are dependent on their relative severity in each cultural group. GD-S will predict more distress and more negative effects, as it is more detrimental in adult life (as contrasted by the potential different effects of GD-P on children).

Hypothesis 4: Appraisal of GD (negative or positive) is one of the coping strategies with such social structural oppression: Self-esteem mediates the effects of appraisal and GD on health and mental health. While negative appraisal increases self-esteem, positive appraisal decreases self-esteem and affects negatively physical and mental health and functioning. Figure 1 illustrates this hypothesis.

\section{Method}

\subsection{Participants and Outcome Measures in the Four Samples}

Table 1 summarizes the demographic characteristics of the four samples.

Participants in sample 1: The first sample consisted of AI adults in the United Stated, primarily living in the state of Oklahoma. The fieldwork of this study was conducted between November of 2010 and May of 2011. Ninety-three percent of participants were enrolled members of a tribe, with representation from 45 different tribes. Data analysis focused on the females $(\mathrm{N}=188)$.

The Independent variable: Measuring Gender Discrimination and cumulative Trauma in the four samples:

The Cumulative Trauma Scale CTS-S (short form) is a measure that is based on the DBTF framework (Kira et al., 2008). The CTS-S is a 32-item instrument that measures cumulative trauma in terms of occurrence, frequency, type, and negative and positive appraisals. It includes six trauma types: collective identity trauma, personal identity trauma, survival trauma, attachment trauma, secondary trauma, and gender discrimination. Collective identity trauma includes traumas related to exposure to war and torture, as well as discrimination based on race, ethnicity, or national origin. Secondary trauma includes traumas related to having witnessed a traumatic event occurring to another individual or group and impacting social interdependence. Personal identity trauma includes traumas related to sexual abuse, rape, incest, and being robbed. Survival trauma includes car accidents, life threatening illnesses, and natural disasters. Attachment trauma includes abandonment by parents. Gender discrimination includes gender discrimination by parents (family) and gender discrimination by society and institutions. An index of betrayal trauma was also constructed that included being led to sexual contact with a caregiver, abandonment by mother or father, and serious rejection in relationships. On each item, participants were instructed to indicate their experience with a traumatic event on a 5-point Likert-type scale $(0=$ never; 4 = many times). If participants endorsed that they had experienced the traumatic event, they were then asked to indicate the effect of the event on a 7-point Likert-type scale $(1=$ extremely positive; $7=$ extremely negative). In the analysis, the appraisal scale was divided into two sub-scales: Positive appraisal $(1-4)$ and negative appraisals (5 - 7). The measure includes some single item measures: one for continuous not-traumatic stress (hassles): "I experienced a nervous breakdown or felt like I was about to have one (e.g., about to lose control) due to seemingly small but recurrent or continuous chronic stresses or hassles". Gender discrimination scale consists of 


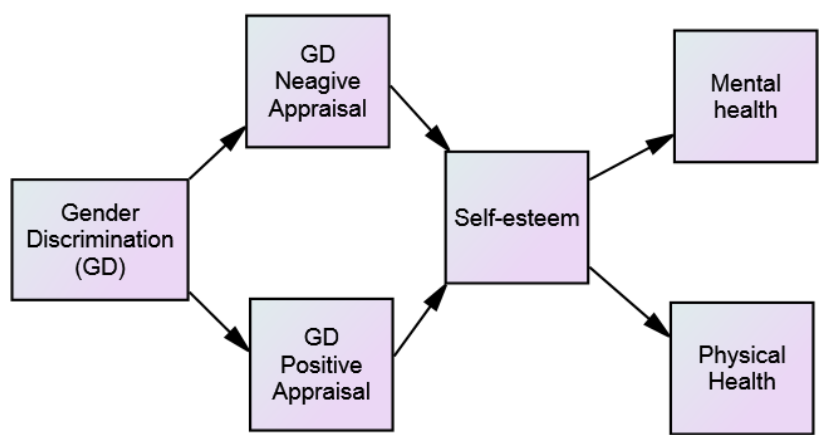

Figure 1. Illustration of the hypothesized dynamics of appraisal with the mediation of self-esteem.

Table 1. The demographic variables of the four samples.

\begin{tabular}{|c|c|c|c|c|}
\hline $\begin{array}{l}\text { Demographic } \\
\text { variable }\end{array}$ & American Indians & Torture survivors & Palestinians & Egyptians \\
\hline Age & $\begin{array}{l}\text { Range }=18-70, M=36.16 \\
S D=14.10\end{array}$ & $\begin{array}{l}\text { Range }=18-68, M=35.37 \\
S D=13.75\end{array}$ & $\begin{array}{l}\text { Range }=18-59, \mathrm{M}= \\
28.98, \mathrm{SD}=8.61\end{array}$ & $\begin{array}{l}\text { Range }=18-65, \mathrm{M}= \\
34.04, \mathrm{SD}=12.34\end{array}$ \\
\hline Education & $\begin{array}{l}\text { 1.8\% up to } 8 \text { years of } \\
\text { education, } 21.1 \% \text { - } 12 \\
\text { years of education, } 5.8 \% \\
\text { vocational education, } 12.2 \% \\
\text { community college, } 28.2 \% \\
\text { some University, } 14.4 \% \\
\text { college graduate, } 10.6 \% \\
\text { graduate degree }\end{array}$ & $\begin{array}{l}31.6 \% \text { minimum writing and } \\
\text { reading skills, } 25 \% \\
\text { elementary education, } \\
29.9 \% \text { secondary education, } \\
13.2 \% \text { high school, .7\% } \\
\text { university, .7\% graduate } \\
\text { level }\end{array}$ & $\begin{array}{l}3.6 \% \text { read and writes; } \\
3.6 \% \text { have intermediate } \\
\text { school; } 10.9 \% \text { have } \\
\text { high school; } 76.4 \% \\
\text { have University degree, } \\
\text { 5.5\% are graduate } \\
\text { students }\end{array}$ & $\begin{array}{l}55.6 \% \text { basic school } \\
\text { education, } 44.4 \% \\
\text { higher than basic } \\
\text { education (university } \\
\text { and above) }\end{array}$ \\
\hline $\begin{array}{l}\text { Living areas and } \\
\text { ethnic origin }\end{array}$ & $\begin{array}{l}18.1 \% \text { live in Indian } \\
\text { reservation, } 46.3 \% \text { live in } \\
\text { rural areas, } 35.6 \% \text { live in } \\
\text { Urban areas, } 92.6 \% \text { are } \\
\text { members of a tribe ( } 40 \\
\text { different tribes) }\end{array}$ & $\begin{array}{l}30 \% \text { Iraqi, } 26.6 \% \\
\text { Bhutanese, } 18.8 \% \text { Burmese, } \\
13.1 \% \text { Somali, the balance } \\
\text { from other } 7 \text { African } \\
\text { countries, Cuba, Russia, } \\
\text { Afghanistan, India and Iran. } \\
\text { All currently live in } \\
\text { Sub-urban areas in the US }\end{array}$ & $\begin{array}{l}\text { 9.1\% lives in Rural } \\
\text { areas; } 30.9 \% \text { lives in } \\
\text { Urban areas and } 60 \% \\
\text { lives in refugee camps }\end{array}$ & $\begin{array}{l}58.9 \% \text { lives in Urban } \\
\text { Areas, and } 41.1 \% \text { lives } \\
\text { in rural areas. }\end{array}$ \\
\hline $\begin{array}{c}\text { Household } \\
\text { income/poverty }\end{array}$ & $\begin{array}{l}83.4 \% \text { reported to belong to } \\
\text { a poor family with many } \\
\text { hardships, while } 16.6 \% \\
\text { reported to never been poor }\end{array}$ & $\begin{array}{l}51 \% \text { reported to be } \\
\text { somewhat poor, } 8 \% \text { reported } \\
\text { to be extremely poor, } 41 \% \\
\text { reported to never been poor }\end{array}$ & $\begin{array}{l}81.8 \% \text { reported to } \\
\text { belong to a poor family } \\
\text { with many hardships }\end{array}$ & $\begin{array}{l}57.5 \% \text { reported to be } \\
\text { poor, } 40.6 \% \text { reported to } \\
\text { be average, and } 1.9 \% \\
\text { reported to be well-off }\end{array}$ \\
\hline Family size & $\mathrm{M}=3.8, \mathrm{SD}=1.96$ & $M=5.37, S D=2.25$ & $\mathrm{M}=7.31, \mathrm{SD}=2.82$ & NA \\
\hline Marital status & Not collected & $\begin{array}{l}55.8 \% \text { married, } 1.3 \% \text { living } \\
\text { with partner, } 19.9 \% \text { single, } \\
3.8 \% \text { divorce; } 12.8 \% \\
\text { widows, } 2.6 \% \text { spouse is } \\
\text { missing, } 3.8 \% \text { spouse lives } \\
\text { back home }\end{array}$ & $\begin{array}{l}42.6 \% \text { married; } 50 \% \\
\text { single; } 7.4 \% \text { divorced }\end{array}$ & $\begin{array}{l}54.1 \% \text { married, } 45.9 \% \\
\text { different unmarried } \\
\text { statuses }\end{array}$ \\
\hline Religion & NA & $\begin{array}{l}\text { 19.1\% Christians, } 4.5 \% \\
\text { Buddhists, 19.7\% Hindus, } \\
\text { 25.5\% Muslim Sunni, 3.2\% } \\
\text { Muslim Shiites, 28.\% other } \\
\text { religious affiliations }\end{array}$ & 100\% Muslim Sunnis & $\begin{array}{l}\text { 88.9\% Muslim Sunnis, } \\
\text { 11.1\% Christians }\end{array}$ \\
\hline
\end{tabular}

two added single-item measures; one for GD-P “I was put down, threatened or discriminated against by some other family members (e.g., parents, siblings) negative attitudes, stereotypes or actions because of my gender: being a boy or girl." and the other for GD-S "I was put down, denied my rights, or discriminated against in the society (not by family members), by some others' negative attitudes, stereotypes or actions, or by institutions because of my gender (being a girl/woman or a boy/man). The answer options include (like other items in the 
scale: 0 = Never; 1 = once; 2 = two times; 3 = three times; 4 = many times).” CTS-S provides us with general scales for two of the cumulative trauma doses: Occurrence and frequency of happenings, two appraisal subscales: negative and positive appraisal. It includes, at this level, four sub-scales for each trauma types.

This instrument has shown adequate internal consistency $(\alpha=.85)$ (Kira et al., 2008, Kira, Fawzi, \& Fawzi, 2012), and test-retest stability (.74 in 6 weeks). Predictive validity was shown as cumulative trauma was significantly correlated with Posttraumatic Stress Disorder $(r=.54, p<.001)$, cumulative trauma related disorders $(r=.24, p$ $<.001)$, and poor health $(r=.37, p<.001)$ (Kira et al., 2008). CTS-S has also shown divergent validity as it was significantly negatively correlated with sociocultural adjustment $(r=-.25, p<.001)$, and futuristic orientation $(r=-.37, p<.001)$. CTS-S has been used with different clinical and community samples of adults and adolescents from a various sociocultural groups and has proven to have adequate reliability (Alpha ranged between .85 and .92) and good construct validity (e.g., Kira et al., 2008, Kira, Lewandowski, Somers, Yoon, \& Chiodo, 2012e, Kira et al., 2012b; Kira et al., 2011a; Kira et al., 2011b) and cross-cultural validity across different cultural groups (e.g., Kira, Fawzi, \& Fawzi, 2012). The two items gender discrimination sub-scale's reliability found to be fair to adequate in previous studies (e.g., Kira, Ashby et al., 2012). The measure has been used in several studies as a comprehensive measure for stress and trauma (e.g., Head, Singh, \& Bugg, 2012; Gillespie \& Gates, 2013; Millender, 2013; Omidy, 2012). In the four studies that used the same scale, Chronbach's a ranged from .83 - .92 for trauma occurrence, and from .83 to .96 for cumulative negative appraisal, and from .82 to .89 for cumulative positive appraisal. While appraisal was not measured in torture survivors, it was measured in the other samples.

\section{Reliability and validity of GD single items:}

There is increased use of single items in research and single items were used to assess positivity/negativity of attitudes toward objects or events (Larsen, Norris, McGraw, Hawkley, \& Cacioppo, 2009). Methodologists proposed that meaningful reliability estimates for single item measures can be calculated using correction of attenuation and factor analysis (e.g., Wanous \& Hudy, 2001). Communality in factor analysis of the single item included in similar measures can be considered a conservative estimate of single-item reliability (e.g., Wanous \& Hudy, 2001). Following Wanous and Hudy's (2001) method of estimating single-item reliability, factor analyses were conducted between all trauma items in negative and positive appraisals and occurrence. Table 2 displays the communalities of GD variables in each sample which indicates fair to adequate reliability indicators. The predictive validity of GD and its single item measures was established in previous studies (Kira et al., 2010, Kira et al., 2012).

\section{Outcome measures in sample 1:}

Binge Eating Scale (BES; Gormally, Black, Daston, \& Rardin, 1982) is a 16-item scale that measures bingeeating behaviors. Each item gives four statements and asks participants to circle the statement that best matches his or her eating behavior and emotions surrounding binge eating. Within each item, each statement is assigned points for the degree to which the statement describes binge eating (ranging from 0 - 3). Higher scores indicate more binge eating attributes. Scores of 17 or less indicated non-binge eating, scored of 18 - 26 indicated moderate binge eating, and severe binge eating was indicated by scores of 27 or higher. BES has shown adequate internal consistency $(\alpha=.85)$ and test-retest reliability $(r=.87, p<.001)$ (Gormally et al., 1982, Greeno, Marcus, $\&$ Wing, 1995). The measure had alpha of .87 in the current data.

Medical Outcome Study, Short-Form-36 version 2 (SF-36; Ware \& Shelbourne, 1992). The SF-36 was developed from the Medical Outcomes Study and has 36-items. It measured the following health concepts: physical functioning, role limitations due to physical/emotional health issues, bodily pain, social functioning, general mental health, vitality, and perceived general health. Participants are asked to indicate their responses to each question based on a Likert-type response choice. Lower scores indicated higher disruptions to functioning based on limitations from physical and mental health. This instrument has shown adequate content, construct, and predictive validity (Ware \& Shelbourne, 1992). It has also shown internal consistency throughout the subscales (Chronbach's $\alpha$ ranging from 0.73 to 0.96 ) and test re-test reliability ( $r$ ranging from .60 to .81). Convergent validity was shown as groups were differentiated in regards to severity of symptoms within the physical health and the mental health constructs (McHorney, Ware, \& Raczek, 1993). In the current data $\alpha=.76$ for general health, $\alpha=.71$ for the measure of mental health, and $\alpha=.94$ for the measure of physical health.

The demographics section was used to collect specific mental and physical health diagnoses. We developed an index of psychiatric comorbidities of mental health diagnoses from these data. Information on the illegal drug use and substance abuse was also collected. 
Table 2. Factor analysis communalities of the GD occurrence and appraisals in the four samples as indicators of their reliabilities.

\begin{tabular}{|c|c|c|c|c|c|c|}
\hline & \multicolumn{2}{|c|}{ GD Occurrence } & \multicolumn{2}{|c|}{ GD Positive Appraisal } & \multicolumn{2}{|c|}{ GD Negative Appraisal } \\
\hline & GDP & GDS & GDP & GDS & GDP & GDS \\
\hline Egyptian Sample & .674 & .696 & .689 & .876 & .643 & .568 \\
\hline American Indian Sample & .695 & .685 & .669 & .679 & .703 & .701 \\
\hline Palestinian Sample & .819 & .669 & .696 & .774 & .750 & .709 \\
\hline Torture Survivor Sample & .769 & .719 & - & - & - & - \\
\hline
\end{tabular}

Participants in sample 2: The participants in this sample consisted of 359 clients from the Center for Torture and Trauma Survivors (CTTS). Participants were screened at the center from April 2008 through September 2009. They include 160 females and 199 males. Ninety-five percent of the participants were new arrivals (2 - 6 months) to the United Stated, and less than five percent had been in the USA for more than a year. Data analysis focused on females $(\mathrm{N}=160)$.

Construction and Translation of Measures

The intake protocol and other measures utilized in the center were first constructed in English and subsequently translated into refugee major languages (Arabic, Bhutanese, and Burmese) by bilingual professionals. Measures were then back-translated by another fluent professional and reviewed for accuracy and culture appropriateness. After confirmation of the accuracy and cultural appropriateness of the translations, the measures were pilot tested in focus groups. Previous studies have supported the psychometrics of the translated instruments with Iraqi refugees (Kira et al., 2006, 2008). For clients who speak only dialects or other languages, an interpreter translated the questionnaire directly to them (Kira et al., 2013c).

Measures in sample 2: In addition to cumulative trauma scale, the following measures were administered:

The Clinician-Administered PTSD Scale (CAPS-2) was developed by Blacke et al. (1990) and is widely used to assess PTSD. It is a structured clinical interview that assesses 17 symptoms rated on frequency and severity on a 5-point Likert-type scale. The CAPS has demonstrated high reliability (alpha ranges between .92 and .99) and has shown good convergent and discriminant validity (Weathers, Keane, \& Davidson, 2001). In this study, we used the frequency sub-scale of CAPS-2 that is currently widely used in psychiatric literature. Elhai et al., 2006 found that the two symptom formats of CAPS (frequency and severity) were highly inter-correlated (from .86 to .93) and were not differentially related to summed PTSD severity scores or PTSD diagnoses. In addition, Betemps, Smith, Baker, and Rounds-Kugler (2003) discovered that the frequency format was associated with both greater reliability and item discrimination than the intensity format. The scale used in this study has high reliability with an alpha of .97. The scale has four factor sub-scales: re-experiencing, avoidance, arousal and emotional numbness, detachment or dissociation (Palmieri et al., 2007). Reliability of the four sub-scales in our sample are adequate to high (alphas are .96, .92, .89 and .85 respectively).

Cumulative Trauma related Disorders Measure Scale (CTD)(Kira et al., 2012c): This 15-item measure was developed using data from six community and clinic samples from adults and adolescent who were Iraqi refugees, Arab Americans, African Americans, Palestinians and Egyptians. It is an index measure that covers 13 different symptoms: depression, anxiety, somatization, dissociation, auditory and visual hallucinations, avoidance of being with people, paranoid ideations, concentration and memory deficits, loss of self-control, feeling suicidal, and feeling like hurting oneself. Exploratory and confirmatory factor analyses found four factors: executive function deficits, suicidality, dissociation, and depression/anxiety comorbidity. The CTD has demonstrated good reliability (ranging from .85 to .98 in five different studies Kira et al. 2012c). Test-retest reliability in a 6 week-interval was .76. This measure has also demonstrated good predictive validity. Different kinds of traumas, and cumulative trauma in general, accounted for significant variance as predictors of CTD symptoms (Kira, Clifford, \& Al-Haider, 2003). Additionally, this measure was highly correlated with PTSD, DASS-A (anxiety) and CES-D (depression) measures, further suggesting its convergent validity. This measure was also negatively correlated with futuristic orientation, socio-cultural adjustment, and post-traumatic growth, supporting its discriminant validity (Kira et al., 2012c). In the current study, the measure had alpha of .90.

Participants in sample 3: Participants included 132 adults who were living in Palestinian territories in Gaza. Of the sample, $58 \%$ were males and $42 \%$ females. The analysis focused on the females (55). 


\section{Translation of the measures}

The measures used in this study, and in study 4, were previously pilot-tested in focus groups, and had previously been shown to have adequate reliability and validity and cultural appropriateness with Iraqi and Arab populations and in Arabic and English languages (e.g., Kira et al., 2001, 2006, 2008). These measures were previously translated into Arabic by three bilingual mental health professionals who met to establish a consensus on the final version. A fourth mental health professional reverse translated each measure to ensure their accuracy, fidelity, and cultural appropriateness (Kira et al., 2013b).

Measures in sample 3: In addition to CTS, PTSD and CTD measures, measures for depression, anxiety, annihilation anxiety, identity salience, self-reported health, and post-traumatic growth, were administered; as follows:

The Center for Epidemiologic Studies Depression Measure (CES-D; Radloff, 1977): is a 20-item scale designed to measure depression in a normal population. Each item is assessed on a 4-point Likert-type scale and reflects the frequency that each symptom is experienced $(0=$ none of the time; $3=$ all of the time). Adequate reliability and validity have been reported for the CES-D. A cutoff score of $\geq 16$ is commonly used for the CES-D to indicate a need for further assessment for the presence of major depressive disorder (Radloff, 1977). High reliability results (ranging from .85 to .92) have been found for the CES-D among various groups. The measure has alpha $=.91$ in the current data.

The Depression Anxiety Stress Scales-Anxiety (DASS-A). The DASS is a 42-item scale developed by Lovibond and Lovibond (1995) that includes three sub-scales that measure depression, anxiety, and stress. The DASS-A is the sub-scale that measures anxiety and consists of 14-items. This measure is increasingly used in different clinical and research settings. Different studies suggest that DASS-A possesses adequate convergent validity, with reliability of .84 in non-clinical samples and .89 and 91 in clinical samples (Crawford \& Henry, 2003; Lovibond \& Lovibond, 1995). DASS-A had alpha of .95 in this study.

The Annihilation Anxiety scale (Kira et al., 2012f) is a three item scale based on the assumption that there are three main sources of annihilation anxiety (AA), personal identity, collective identity survival threats (traumas), and threats from societal structural inequalities (e.g., extreme poverty). These three sources represent the different sources of AA. The measure includes items that represent each area of annihilation concerns. For instance, the survey asks: "Because of what has happened to me personally or is happening to me personally, I sometimes worry that I just lose my sense of self (I worry that I will cease to exist as an individual person)”. The answer is structured on 5-pointLikert-type scale (5 being strongly agreed and 1 being strongly disagree). The 3-item scale has been used with Iraqi refugees in the United States and three samples of Palestinian adults and adolescents, and has shown to have good reliability (alphas ranged between .90 and .95). Kira et al. (2012f) have also provided evidence for the discriminant and convergent validity for this measure. The measure had alpha of .92 in the current sample.

Identity Salience scale (Kira et al., 2011b) is a 10-items scale. The answer of scale questions is based on 7-point Likert-type scale (1 being completely disagrees and 7 being absolutely agree). High scores on the scale indicate higher group identity salience and low scores indicate more personal identity salience. Based on exploratory and confirmatory factor analysis, the measure has two sub-scales: Identity commitment, a 6-item subscale that measures the degree of commitment to one's national or ethnic group. It asks questions like "When my group is threatened its interest come first before mine”. The second sub-scale measures identity militancy and has 4 items. It includes questions like "I am ready to die for the honor of my group to which I belong to". The total scale alpha coefficient is .80in the current data.

Self-reported health is a single item on a 4-point Likert-type scale that asks about general health, with higher scores indicated poor health status. The scale, in the current study, is highly correlated with age $(r=.46, p=.000)$, negative appraisal of traumatic events $(r=.36, p=.001)$, CTD $(r=.33, p=.001)$, cumulative trauma $(r=.32$, $p=.001)$, PTSD $(r=.30, p=.001)$, and fear of death, $(r=.26, p=.001)$; and negatively correlated with stress related growth $(r=-.13, p=.01)$ and futuristic orientation $(r=-.12, p=.01)$.

Participants in sample 4: Participants were 432 mental health clients who attended the Zagazik University outpatient mental health clinic in Egypt. They included all patients admitted from May 1, 2010 to April 30, 2011. Data analysis focused on females $(\mathrm{N}=207)$.

Measures in sample 4: In addition to CTS, PTSD, CES-D, DASS-A measures, the Rosenberg self-esteem scale was administrated, in addition to diagnostic data and computed comorbidity indexes (number of comorbid mental health and physical health conditions): 
The Rosenberg self-esteem scale (RSES), developed by Dr. Morris Rosenberg (1965) and is a 10-item scale that measures global self-esteem. Each item is rated on a 4-point Likert-type scale from strongly agree to strongly disagree and scored from 0 - 3. The scale is divided by five positively worded and five negatively worded statements. The RSES has been translated and adapted to various languages including Arabic. Rosenberg reported good psychometrics for the scale and its reliability ranging from .85 to .88. For the current Arabic sample alpha was .87.

Diagnostic Data: DSM-IV-TR five axes diagnoses, including GAF (general assessment of functioning) were assigned by the clinic psychiatrists. Comorbidity indexes for mental disorders and for physical disorders were established for each participant.

\subsection{Procedures}

The data were collected in previous studies and reported in previous publications, in which GD was reported only for the torture survivors' data (Kira et al., 2010; Kira et al., 2012). These samples were chosen as they included the same measure of cumulative trauma and trauma types including GD, with different and similar outcome measures, and as they represent different cultures and populations which were optimal for pilot research to test the study hypothesis. All the four studies were previously reported in peer reviewed journals. The data sets were available as part of the archives of a research center for cumulative trauma that was coordinating different research projects. The authors received permission from the original authors to use the data.

\section{Invariance Analysis}

Although formal measurement invariance testing was not possible because GD measures were comprised of only one or two items, we could explore sample invariance for the coefficients from the regressions of PTSD on GD (and later on CTD variables) in three of the samples that have the same PTSD outcome measure. These tests are comparable to tests of the sample x GD interaction effect. More specifically, we conducted multiple groups' regression analyses and statistically compared regression coefficients between the different samples. We used the Model Test option (producing a Wald $\chi^{2}$ ) in Mplus to compare specific parameter estimates (beta coefficients) between samples. In the present analysis, for PTSD, we used the Model Test option to conduct separate comparisons of beta coefficients (i.e., sample 2 (torture survivor samples) = sample 3 (Egyptian sample); sample 3 = sample 4 (Gaza sample); and sample 2 = sample 4 ).

We initially tested the two components of GD (discrimination by society and discrimination by parents). First, for discrimination by society, results revealed no significant differences between coefficients for all three of the comparisons, $\mathrm{W}=\chi^{2}(1, \mathrm{~N}=412)=.69, p=.405, \mathrm{~W}=\chi^{2}(1, \mathrm{~N}=412)<.00, p=.999$, and $\mathrm{W}=\chi^{2}(1, \mathrm{~N}=412)=.64$, $p=.424$, for the tests comparing samples 2 and 3, 3 and 4, and 2 and 4, respectively. Likewise, for discrimination by parents, no significant differences emerged in all three comparisons, $\mathrm{W}=\chi^{2}(1, \mathrm{~N}=412)=.01, .18$, and .03, respectively, $p s>.671$. Not surprising, tests involving the GD composite score also revealed no sample differences in the path coefficients, $p s>.389$.

For the CTD (cumulative trauma disorders) scores, analyses were limited to samples 2 and 4 (the only samples that included this variable). Again the Model Test option in Mplus was used to directly compare the coefficients for the GD components between the groups. In each analysis, a CTD score was regressed on discrimination by society and discrimination by parents. Then the individual regression coefficients associated with each effect were compared across samples. The effect of discrimination by society in predicting CTD scores was significantly larger for sample 2 (torture survivors sample) $(\beta=.32)$ than it was for sample 4 (Gaza) $(\beta=.20)$, W= $\chi^{2}(1, \mathrm{~N}=205)=3.93, p=.047$. Separate tests of the individual CTD subscales revealed differences between the samples for the Dissociation/ Psychosis subscale, $\mathrm{W}=\chi^{2}(1, \mathrm{~N}=205)=4.13, p=.042$, and for the Suicidality subscale, $\mathrm{W}=\chi^{2}(1, \mathrm{~N}=205)=4.09, p=.043$. In each comparison, the statistically significant effect for discrimination by society was greater for sample $2(\beta=.30$ for Dissociation/Psychosis, $\beta=.30$ for Suicidality) than it was for the nonsignificant effects that emerged for sample $4(\beta=.14$ for Dissociation/Psychosis, $\beta=.01$ for Suicidality). None of the Model Test comparisons involving discrimination by society indicated those effects were significantly different between the samples, $p s>.161$, nor did discrimination by parents account for significant variation in any of the CTD scores, $p \mathrm{~s}>$.073. Similar invariance was found for the appraisal measures. This provides initial evidence for the predictive validity of the model. 


\section{Data Analysis}

Partial correlations was conducted between gender discrimination, gender discrimination by parent, gender discrimination by society, negative appraisal of gender discrimination, positive appraisal of gender discrimination, and all outcome variables in each study, controlling for age, education, marital status, and socio-economic status. To test the theoretical model of the reversed outcome of positive appraisal of GD as outcome of oppression process and the mediation of the negatively affected self-concept, we tested a plausible path model for Egyptian sample (it is the only sample that has the self-esteem variable included in the measures) that match the discussed theoretical framework in hypothesis VI, for direct, indirect (mediated) and total effects of appraisals on mental health variables. We used IBM SPSS 22and AMOS22 software in data analysis. We chose maximum likelihood parameter estimation over other estimation methods (Kline, 2005). Because the percentage of missing data was less that 5\% we used a mean imputation procedure. Model fit indices in SEM analyses were selected in accordance with several recommendations and included the normed 2 test statistic (2/df), the root mean square error of approximation (RMSEA) and the comparative fit index (CFI). 2/df values $<5.0$ are considered acceptable; RMSEA values 0.05 indicate close fit, values 0.05 to 0.08 indicate reasonable fit, and values $>0.10$ indicate poor fit. CFI values > 0.95 indicate good fit (e.g., Kline, 2005; Hu \& Bentler, 1999). We trimmed the models by eliminating paths that were not significant to provide a more parsimonious summary of the inter-relationships among variables. The initial and final models do not deviate from the theoretical models. We used bootstrapping procedures ( $\mathrm{N}=10,000$ samples) with bias-corrected confidence intervals to test the significance of the direct and indirect (mediated or partially mediated) effects of each variable in the model. Additionally, we tested the non-linearity hypothesis using curve-estimation procedure to test the nonlinear effects of cumulative dynamics hypothesis.

\section{Results}

Results supported the first hypothesis. Gender discrimination was associated with decreased mental health, heightened PTSD, CTD, anxiety, and annihilation anxiety, in all the samples that these variables were measured. In AI/NA, GD was associated with binge eating, lower physical and social functioning, lower general mental health, and perceived general health, as well as with psychiatric comorbidities, illegal drug use and substance abuse. In Palestinians, GD was associated with CTD, PTSD, depression, anxiety, and annihilation anxiety. In torture survivors, GD was associated with CTD and PTSD. In Egyptians, GD was associated with PTSD, and anxiety. Gender discrimination was associated with suicidality in the sample of torture survivors (Sample 2), and with dissociation/psychosis, executive function deficits, in the sample of Palestinians (Sample 3) and torture survivors (Sample 2). It was also associated with decreased self-esteem, global assessment of functioning (GAF), and futuristic orientation (sample 4) (Table 3 includes more details).

Results of SEM indicated similar results. In the Egyptian sample, GD predicted negative self-esteem, reduced (GAF) and increased PTSD, depression and mental health comorbidity (the model had good fit: Chi Square = 20.574; d.f. $=12 ; p=.168 ; C F I=.971 ; R M S E A=.059)$. Self-esteem, as has been predicted, mediated the effects of gender discrimination on mental health (see Figure 2; see also Kira et al., 2010, 2012, for torture survivors). Because all participants were from severely traumatized populations, to eliminate the potential effect of other trauma types (collective identity, personal identity, attachment, survival and secondary traumas), we added them to the models in separate analyses. While most of the other trauma types were predictive of negative mental health, GD and positive appraisal of GD continued to be highly predictive of negative mental and physical health outcomes.

Results supported the second hypothesis. Gender discrimination, as identity trauma that intersects with similar traumas, was associated with identity salience, personal identity, collective identity, role identity (achievement), attachment, secondary, betrayal, survival, cumulative stress, and community violence traumas. It was associated with uprootedness trauma in Palestinians and American Indians who suffered uprootedness. The highest associations were with betrayal and personal identity traumas (Table 3). Gender discrimination may be related to feeling of betrayal be parents and social systems, and is directly related to identity.

Further curve estimation regression analysis for the effects of GD in torture survivors sample (on PTSD and CTD, found significant linear and quadratic effects $\left(F=3.29^{*}\right)$ on PTSD, and significant linear, quadratic $(F=$ $\left.7.37^{* * *}\right)$ and cubic $\left(\mathrm{F}=5.47^{* * *}\right)$ effects on CTD. For American Indians sample, GD predicted significant linear, quadratic $\left(\mathrm{F}=3.22^{*}\right)$, and cubic $\left(3.04^{*}\right.$ ) effects on mental health. For Palestinian and Egyptian samples, there 
Table 3. Partial correlation, between gender discrimination (GD) and mental health variables and trauma types, controlling for education, marital status and socio-economic status (SES).

\begin{tabular}{|c|c|c|c|c|}
\hline & American Indians & Palestinians & Torture Survivors & Egyptian MH Clinic \\
\hline General Assessment of Functioning (GAF) & $\underline{-}$ & $\underline{-}$ & $\underline{-}$ & $-.11^{*}$ \\
\hline Mental Health & $-.21^{* * *}$ & 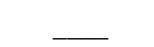 & 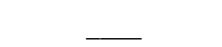 & $\underline{ }$ \\
\hline Bing Eating Scale & $.22^{* * *}$ & 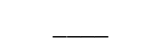 & 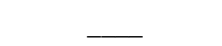 & 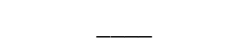 \\
\hline Alcohol Abuse & $.16^{* *}$ & _ & $\underline{ }$ & 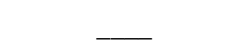 \\
\hline DASS-A Anxiety & $\underline{-}$ & $21^{*}$ & 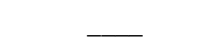 & $.10^{*}$ \\
\hline CES-D Depression & 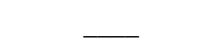 & $.22^{*}$ & $\underline{-}$ & .04 \\
\hline PTSD & 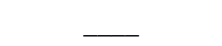 & $.28^{* *}$ & $.10^{*}$ & $.15^{* * *}$ \\
\hline CTD & 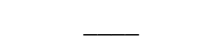 & $.31^{* * *}$ & $.19^{* * *}$ & 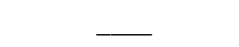 \\
\hline CTD-Suicidality & $\underline{-}$ & .13 & $.16^{* *}$ & $\underline{-}$ \\
\hline CTD-Depression Anxiety Somatization Comorbidity & 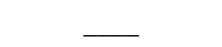 & $.30^{* * *}$ & $.10+$ & $\underline{-}$ \\
\hline CTD-Executive Functions Deficits & $\underline{-}$ & $.17^{*}$ & $.14^{*}$ & $\underline{-}$ \\
\hline CTD-Dissociation/ Psychosis & 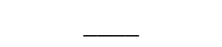 & $.25^{* *}$ & $.14^{*}$ & $\underline{-}$ \\
\hline Annihilation Anxiety & - & $.22^{*}$ & - & $\underline{ }$ \\
\hline Self-Esteem & $\underline{-}$ & $\underline{-}$ & 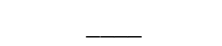 & $-.09^{*}$ \\
\hline Identity Salience & $\underline{-}$ & $.25^{* *}$ & 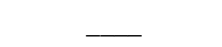 & $\underline{-}$ \\
\hline Personal Identity Traumas & $.41^{* * *}$ & $.43^{* * *}$ & $.28^{* * *}$ & $.11^{*}$ \\
\hline Collective Identity Traumas & $.12^{*}$ & $.25^{* *}$ & $.17^{* *}$ & -.02 \\
\hline Attachment Traumas & $.20^{* * *}$ & $.29^{* * *}$ & $.42^{* * *}$ & $.09+$ \\
\hline Achievement Traumas & $.17^{* *}$ & .11 & $.13^{*}$ & $.15^{* * * *}$ \\
\hline Survival Traumas & $.33^{* * *}$ & $.44^{* * *}$ & .03 & $.16^{* * *}$ \\
\hline Uprootedness Trauma & $.30^{* * *}$ & $.37^{* * *}$ & .05 & .04 \\
\hline Betrayal Traumas & $.35^{* * *}$ & $.83^{* * * *}$ & $.45^{* * *}$ & $.16^{* * *}$ \\
\hline Secondary Traumas & $.27^{* * *}$ & $.46^{* * *}$ & $.15^{* *}$ & $.12^{*}$ \\
\hline Cumulative Stress Trauma & $.20^{* * *}$ & $.32^{* * *}$ & $.31^{* * *}$ & .08 \\
\hline Community Violence & 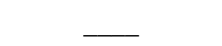 & $.42^{* * *}$ & $.13^{*}$ & 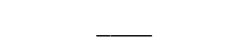 \\
\hline
\end{tabular}

Note: $+p<.10{ }^{*} p<.05 .{ }^{* *} p<.01,{ }^{* * *} p<.001$; related disorders (complex PTSD).

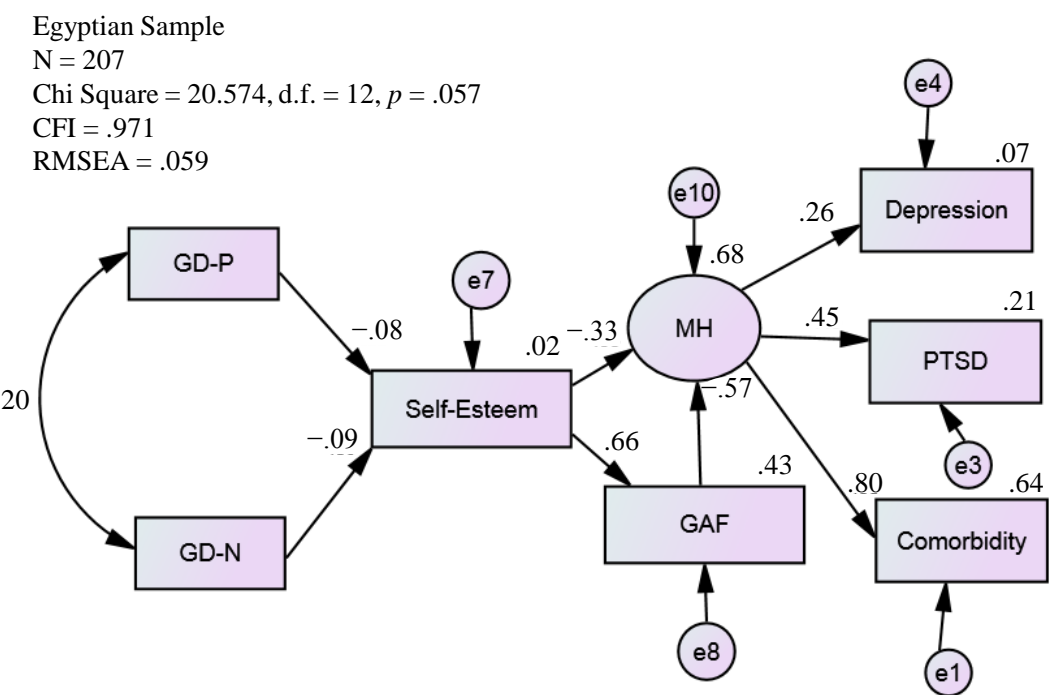

Note: GAF = general assessment of functioning; $\mathrm{MH}$ = mental health; GD-NA = gender discrimination negative appraisal; GD-PA = gender discrimination positive appraisal.

Figure 2. Path diagram for the direct standardized effects of negative and positive appraisal of GD, mediated by self-esteem on mental health variables in the Egyptian sample. 
were technical statistical difficulties in computing curve estimation regression. The effects of cumulative trauma on PTSD and CTD as well other important mental health variables were found to be linear and nonlinear in all samples). These results cautiously support the non-linear type III trauma model of GD.

Results supported the third hypothesis and provided more specific data on the different nature of each type of GD. Gender discrimination by parents and family members was not associated with PTSD, DASS-Anxiety, CES-D depression, AA, or reduced self-esteem. Conversely, it was associated with decreased mental health, CTD, and CTD-depression and anxiety/somatization comorbidity, physical and mental health comorbidities, and with binge disordered eating. Gender discrimination by social institutions and interpersonal intergroup dynamics had the worst mental health effects, compared with gender discrimination by parents. It was associated with PTSD, DASS-A, anxiety, AA, ISMI, CTD, and CTD-executive function deficits, CTD-depression and anxiety comorbidity, CTD-dissociation and psychosis, and binge eating. However, gender discrimination by social institutions was also associated with post-traumatic growth. Gender discrimination by social institutions seemed to be associated with more negative outcomes, when compared to gender discrimination by parents and family members, except for in AI/NAs. For AI/NA's gender discrimination by parents and family members was either equal to or worse than gender discrimination by social institutions, in terms of severity (Table 4).

Hypothesis 4: Results supported the fourth hypothesis (The reverse effects of appraisal under the oppression condition), especially in the highly gender discriminating cultures. Results of SEM were straightforward in Egyptian sample that was feasible to analyze. In the Egyptian sample, self-esteem mediated the effects of both appraisal types on mental health. Positive appraisal of GD predicted significant decrease in self-esteem and GAF and increased PTSD, depression and mental health comorbidity (see Figure 2 and Table 5).

\section{Discussion}

Gender discrimination is associated with significant decreased in mental health across cultures regardless of the measurement strategy used to measure mental health. Its negative effects on physical health were found but not as consistently significant. The negative effects of gender discrimination by social institutions were consistent across cultures for these adult samples, while the negative effects of GD by parents were not as highly consistent which may depend on the severity of GD types in different cultures and in different age groups. However, we should emphasize that the found association are about symptoms (or their severity) and not a particular mental disorder or diagnosis per se. Gender discrimination, as identity trauma, intersected with other identity traumas across cultures. The negative effects of positive appraisal of GD mediated by self-esteem, found in the Egyptian sample highlighted important dynamics and need further replications.

The significance of the present study rests in three basic premises. It is the first study that uses the DBTF framework to study GD as type III continuous and ongoing trauma framework which has important ramification in the way we assess and treat its negative consequences, as we will further discuss. It is the first study to test the salience of the negative mental and physical effects of GD across different cultures and measurement strategies. Further it is the first study to assess the negative effects of internalizing GD (through positive appraisal), and the positive effects of rejecting GD (through negative appraisal that minimize the harm caused by GD to self-esteem).

\section{GD as Type III Continuous trauma}

The traumatology perspective of GD proved to be a robust convincing approach across the four studies. The negative mental health associations with GD, as continuous traumatic independent stressors that proliferate to other dependent and related stressors, proved to be a robust finding across studies that represented different cultures and different healthy and unhealthy populations, using different measurement strategies to mental and physical health. Across the four samples, gender discrimination was shown to predict the severity of post-trauma spectrum symptoms including PTSD, complex PTSD and mental health comorbidities. The four studies used different samples from different cultures with different levels of GD intensity in each. The four studies used different sample sizes that each has different characteristics, different recruitment methods, and different measures for health and mental health. However, the negative effects of GD, as type III chronic trauma for females were stable and the results were replicated across completely different populations in terms of cultures, religions, history, demographics, and trauma profiles. These relationships hold across many assessment tools and across different outcome measures.

Pathways to the Negative Effects of GD

Potentially interrelated different dynamics and pathways were or may be suggested to explain GD's negative 
Table 4. Partial correlation between gender discrimination by parents (GD-P), gender discrimination by social institutions (GD-S) and mental health variables and trauma types, controlling for education, marital status and socio-economic status (SES).

\begin{tabular}{|c|c|c|c|c|c|c|c|c|}
\hline & \multicolumn{2}{|c|}{ American Indians } & \multicolumn{2}{|c|}{ Palestinians } & \multicolumn{2}{|c|}{ Egyptian MH Clinic } & \multicolumn{2}{|c|}{ Torture Clinic } \\
\hline & GD-P & GD-S & GD-P & GD-S & GD-P & GD-S & GD-P & GD-S \\
\hline $\begin{array}{c}\text { Physical and } \\
\text { Mental Comorbidities }\end{array}$ & $.13^{*}$ & -.01 & - & $\longrightarrow$ & -.06 & $.14^{* *}$ & - & - \\
\hline GAF & 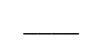 & 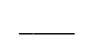 & 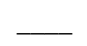 & - & -.05 & $-.09+$ & 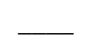 & - \\
\hline Mental Health & $-.22^{* * *}$ & $-.10+$ & 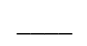 & 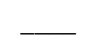 & 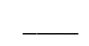 & 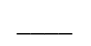 & 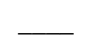 & 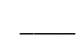 \\
\hline General Health & -.07 & $-.10+$ & $.21^{*}$ & .10 & 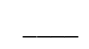 & 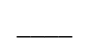 & 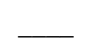 & 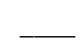 \\
\hline Bing Eating Scale & $.13^{*}$ & $.14^{* *}$ & 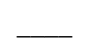 & 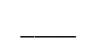 & 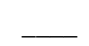 & 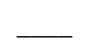 & 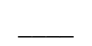 & 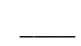 \\
\hline Alcohol Abuse & $.11+$ & .08 & 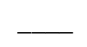 & 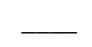 & 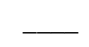 & 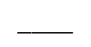 & 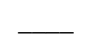 & - \\
\hline DASS-A Anxiety & - & 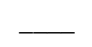 & .09 & $.22^{*}$ & .01 & $.11^{*}$ & 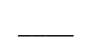 & 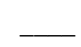 \\
\hline $\begin{array}{l}\text { CES-D } \\
\text { Depression }\end{array}$ & - & - & .07 & $.26^{* *}$ & -.03 & .06 & - & - \\
\hline PTSD & 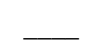 & $\longrightarrow$ & .11 & $.30^{* * *}$ & .03 & $.16^{* * *}$ & .05 & $.12^{*}$ \\
\hline CTD & 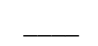 & 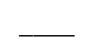 & $.20^{*}$ & $.29^{* *}$ & 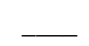 & 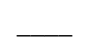 & $.12^{*}$ & $.19^{* * *}$ \\
\hline Suicidality & 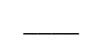 & 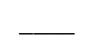 & .14 & .08 & 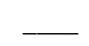 & 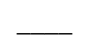 & $.12+$ & $.16^{* *}$ \\
\hline $\begin{array}{l}\text { Depression Anxiety/ } \\
\text { Somatization Comorbidity }\end{array}$ & $\longrightarrow$ & - & $.16^{*}$ & $.29^{* * *}$ & - & - & .06 & $.10+$ \\
\hline $\begin{array}{l}\text { Loss of Control and } \\
\text { Executive Functions Deficits } \\
\text { Comorbidity }\end{array}$ & - & - & .06 & $.19^{*}$ & - & - & $.11+$ & $.13^{*}$ \\
\hline $\begin{array}{l}\text { Dissociation/Psychosis } \\
\text { Comorbidity }\end{array}$ & - & 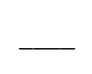 & .14 & $.24^{*}$ & - & - & $.10+$ & $.14^{*}$ \\
\hline Annihilation Anxiety & - & 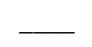 & 11 & $.22^{*}$ & 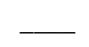 & - & 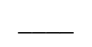 & 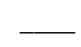 \\
\hline Self-Esteem & - & - & - & - & -.01 & $-.11^{*}$ & - & - \\
\hline Identity Salience & 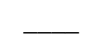 & 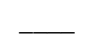 & $.26^{* *}$ & .14 & - & - & - & 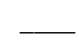 \\
\hline Personal Identity Traumas & $32^{* * *}$ & $.18^{* * *}$ & $.43^{* * *}$ & $.27^{* *}$ & .01 & $.13^{* *}$ & $.24^{* * *}$ & $.24^{* * *}$ \\
\hline $\begin{array}{l}\text { Collective } \\
\text { Identity Traumas }\end{array}$ & $32^{* * *}$ & $.27^{* * *}$ & -.09 & $-.28^{* * *}$ & $.09+$ & $-.10^{*}$ & .04 & $.24^{* * *}$ \\
\hline $\begin{array}{l}\text { Attachment } \\
\text { Traumas }\end{array}$ & $15^{* *}$ & $.12^{*}$ & $.26^{* *}$ & $.21^{*}$ & -.02 & $.13^{* *}$ & $.33^{* * *}$ & $.39^{* * *}$ \\
\hline $\begin{array}{c}\text { Achievement } \\
\text { (Role Identity) Traumas }\end{array}$ & $.17^{* *}$ & .11 & $.28^{* * *}$ & -.06 & $.09+$ & $11 .^{*}$ & $.10+$ & $.12^{*}$ \\
\hline $\begin{array}{l}\text { Survival } \\
\text { Traumas }\end{array}$ & $.28^{* * *}$ & $.27^{* * *}$ & $.35^{* * *}$ & $.34^{* * *}$ & .08 & $.14^{* *}$ & .01 & .04 \\
\hline $\begin{array}{l}\text { Uprootedness } \\
\text { Trauma }\end{array}$ & $.32^{* * *}$ & $.25^{* * *}$ & $.30^{* * *}$ & $.29^{* * *}$ & -.03 & .07 & .04 & .05 \\
\hline Betrayal Traumas & $.37^{* * *}$ & $.33^{* * *}$ & $.65^{* * *}$ & $.67^{* * *}$ & -.00 & $.20^{* * *}$ & $.36^{* * *}$ & $.41^{* * *}$ \\
\hline $\begin{array}{l}\text { Secondary } \\
\text { Traumas }\end{array}$ & $.27^{* * *}$ & $.19^{* * *}$ & $.38^{* * *}$ & $.34^{* * *}$ & -.05 & $.14^{* *}$ & .06 & $.19^{* * *}$ \\
\hline Cumulative Stress Trauma & $.19^{* * *}$ & $.27^{* * *}$ & $.18+$ & $.31^{* * * *}$ & .04 & .07 & $.23^{* * *}$ & $.29^{* * *}$ \\
\hline Community Violence & 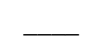 & 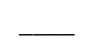 & $.31^{* * *}$ & $.34^{* * *}$ & - & - & .03 & $.19^{* * *}$ \\
\hline
\end{tabular}

Note: $+p<.10,{ }^{*} p<.05,{ }^{* *} p<.01,{ }^{* * *} p<.001$. ___ variables were not measured. GD-P = Gender discrimination by parents and family members; GD-S = gender discrimination by society, institutions and culture at large; PTSD = post-traumatic stress disorder; CTD = cumulative trauma related disorders (complex PTSD). 
Table 5. The direct and indirect standardized effects of negative and positive appraisals of gender discrimination, their significance and 95\% confidence intervals, on mental and physical health, mediated by self-esteem in the Egyptian females sample $(\mathrm{N}=207)$.

\begin{tabular}{|c|c|c|c|c|c|c|}
\hline \multirow[b]{2}{*}{ Causal Variables } & \multicolumn{6}{|c|}{ Endogenous Variables } \\
\hline & Self-Esteem & GAF & MH & PTSD & Depression & Comorbidity \\
\hline \multicolumn{7}{|l|}{ GD-NA } \\
\hline Direct Effects & $\begin{array}{c}-.09 \\
(-.18 / .09)\end{array}$ & & $\longrightarrow$ & - & - & $\longrightarrow$ \\
\hline Indirect Effects & $\longrightarrow$ & $\begin{array}{c}-.06 \\
(-.12 / .05)\end{array}$ & $\begin{array}{c}.06 \\
(-.06 / .13)\end{array}$ & $\begin{array}{c}.03 \\
(-.03 / .07)\end{array}$ & $\begin{array}{c}.02 \\
(-.02 / .04)\end{array}$ & $\begin{array}{c}.05 \\
(-.05 / .10)\end{array}$ \\
\hline Total Effects & $\begin{array}{c}-.09 \\
(-.18 / .09)\end{array}$ & $\begin{array}{c}-.06 \\
(-.12 / .05)\end{array}$ & $\begin{array}{c}.06 \\
(-.06 / .13)\end{array}$ & $\begin{array}{c}.03 \\
(-.03 / .07)\end{array}$ & $\begin{array}{c}.02 \\
(-.02 / .04)\end{array}$ & $\begin{array}{c}.05 \\
(-.05 / .10)\end{array}$ \\
\hline \multicolumn{7}{|l|}{ GD-PA } \\
\hline Direct Effects & $\begin{array}{c}-.08^{*} \\
(-.14 /-.01)\end{array}$ & $\longrightarrow$ & & $\longrightarrow$ & $\longrightarrow$ & $\longrightarrow$ \\
\hline Indirect Effects & - & $\begin{array}{c}-.05^{*} \\
(-.10 /-.01)\end{array}$ & $\begin{array}{c}.06^{*} \\
(.01 / .11)\end{array}$ & $\begin{array}{c}.03^{*} \\
(.01 / .05)\end{array}$ & $\begin{array}{c}.02^{*} \\
(.01 / .03)\end{array}$ & $\begin{array}{c}.05^{*} \\
(.01 / .08)\end{array}$ \\
\hline Total Effects & $\begin{array}{c}-.08^{*} \\
(-.14 /-.01)\end{array}$ & $\begin{array}{c}-.05^{*} \\
(-.10 /-.01)\end{array}$ & $\begin{array}{c}.06^{*} \\
(.01 / .11)\end{array}$ & $\begin{array}{c}.03^{*} \\
(.01 / .05)\end{array}$ & $\begin{array}{c}.02^{*} \\
(.01 / .03)\end{array}$ & $\begin{array}{c}.05^{*} \\
(.01 / .08)\end{array}$ \\
\hline \multicolumn{7}{|l|}{ Self-Esteem } \\
\hline Direct Effects & & $\begin{array}{c}.66^{* *} \\
(.59 / .72)\end{array}$ & $\begin{array}{c}-.33^{* *} \\
(-.51 /-18)\end{array}$ & $\longrightarrow$ & - & - \\
\hline Indirect Effects & & $\longrightarrow$ & $\begin{array}{c}-.38^{* *} \\
(-.47 /-.26)\end{array}$ & $\begin{array}{c}-.32^{* *} \\
(-.44 /-.20)\end{array}$ & $\begin{array}{c}-.18^{*} \\
(-.27 /-.07)\end{array}$ & $\begin{array}{c}-.57^{* *} \\
(-.63 /-.31)\end{array}$ \\
\hline Total Effects & & $\begin{array}{c}.66^{* *} \\
(.59 / .72)\end{array}$ & $\begin{array}{c}-.71^{* *} \\
(-.85 /-.59)\end{array}$ & $\begin{array}{c}-.32^{* *} \\
(-.44 /-.20)\end{array}$ & $\begin{array}{c}-.18^{*} \\
(-.27 /-.07)\end{array}$ & $\begin{array}{c}-.57^{* *} \\
(-.63 /-.31)\end{array}$ \\
\hline \multicolumn{7}{|l|}{ GAF } \\
\hline Direct Effects & - & $\longrightarrow$ & $\begin{array}{c}-.57^{* *} \\
(-.70 /-.40)\end{array}$ & - & - & - \\
\hline Indirect Effects & & & $\longrightarrow$ & $\begin{array}{c}-.26^{* *} \\
(-.36 /-.17)\end{array}$ & $\begin{array}{c}-.15^{*} \\
(-.22 /-.06)\end{array}$ & $\begin{array}{c}-.45^{* *} \\
(-.57 /-.31)\end{array}$ \\
\hline Total Effects & & & $\begin{array}{c}-.57^{* *} \\
(-.70 /-.40)\end{array}$ & $\begin{array}{c}-.26^{* * *} \\
(-.36 /-.17)\end{array}$ & $\begin{array}{c}-.15^{*} \\
(-.22 /-.06)\end{array}$ & $\begin{array}{c}-.45^{* *} \\
(-.57 /-.31)\end{array}$ \\
\hline \multicolumn{7}{|l|}{ MH } \\
\hline Direct Effects & & - & $\longrightarrow$ & $\begin{array}{c}.46^{* *} \\
(.32 / .56)\end{array}$ & $\begin{array}{c}.26^{*} \\
(.10 / .38)\end{array}$ & $\begin{array}{c}.80^{* *} \\
(.65 / .92)\end{array}$ \\
\hline Indirect Effects & & - & 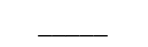 & - & 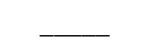 & - \\
\hline Total Effects & & & $\longrightarrow$ & $\begin{array}{c}.46^{* *} \\
(.32 / .56)\end{array}$ & $\begin{array}{c}.26^{*} \\
(.10 / .38)\end{array}$ & $\begin{array}{c}.80^{* *} \\
(.65 / .92)\end{array}$ \\
\hline$R^{2}$ & .02 & .43 & .68 & .21 & .07 & .64 \\
\hline
\end{tabular}

Note: GAF = general assessment of functioning; $\mathrm{MH}=$ mental Health; GD-NA = gender discrimination negative appraisal; GD-PA = gender discrimination positive appraisal. $+p<.10,{ }^{*} p<.05,{ }^{* *} p<.01$.

emotional, physical and behavioral effects. First is the nature of GD as independent continuous identity trauma that proliferates to subsequent dependent traumas, compared to less serious type I or even type II traumas. Among suggested related dynamics that are responsible for its severe effects are: continual betrayal and persistent rejection by close relatives and influential social institutions and networks (Freyd, DePrince, \& Gleaves, 2007; Kira, Lewandowski, Ramswamy et al., 2013), chronic stereotype threat (continuous experience of anxiety situations where a female has the potential to confirm a negative stereotype about her gender) (for example about competency in math )that negatively affect their performance and level of functioning (e.g., Steele, Spencer, \& Aronson, 2002; Aronson, Quinn, \& Spencer, 1998; Woodcock, Hernandez, Estrada, \& Schultz, 
2012), continuous identity threat (e.g., Purdie-Vaughns, Steele, Davis, Ditlmann, \& Crosby, 2008), and genderbased rejection sensitivity (heightened sensitivity (expect, perceive and overreact) to rejection based on devalued status) (London, Downey, Romero-Canyas, Rattan, \& Tyson, 2012).

Another possible pathway to the negative effects of GD is the profound traumatic primary and secondary impact of gender-based violence (GBV) (e.g., intimate partner violence; sexual abuse by non-intimate partners; sex trafficking, forced prostitution, exploitation of labor, and debt bondage of women and girls; physical and sexual violence against prostitutes; sex selective abortion, female infanticide, and the deliberate neglect of girls, rape in war , female genital mutilation, honor killing) on the lives of women and girls that reverberates socially with secondary and tertiary (across generation) traumatization (e.g., Watts \& Zimmerman, 2002). GBV is dependent on the proliferation dynamics of GD. Some forms of GBV are not unique incidents but are ongoing, and can even continue for decades and proliferate to more different traumas. "Violence against women is one of the crucial mechanisms by which women are forced into a subordinate position compared with men.” (UN Declaration on the Elimination of Violence against Women, 23 February, 1994). GBV is a result of GD proliferation dynamics (Kira et al., 2013a). Women exposed to physical/psychological intimate partner violence had a higher incidence and severity of depressive and anxiety symptoms, PTSD, and thoughts of suicide and a higher incidence of suicide attempts, and high comorbidity of PTSD with other disorders. The incidence of single PTSD diagnosis (without other comorbid disorders) is very rare (Pico-Alfonso, Garcia-Linares, \& Celda-Navarro, 2006; Afifi, MacMillan, \& Cox, 2009; Rees et al., 2011; Sullivan, 2012), which all have been showed cross-culturally in two samples of the current study that measured comorbidities.

One of the key dynamics leading to the negative effects of GD is its adverse impact on self-concept, and perceived efficacy which may impact negatively level of functioning. Females who are oppressed, discriminated against, or marginalized due to their gender, face threats to their social value. They may face sexism and gender related micro (e.g., sexual harassment) and macro-aggressions (e.g., gender-based violence) and threat to their sense of belonging and acceptance compared with the dominant, and more socially favored gender. Women, especially in some traditional cultures, are assigned lower values placed on their social identities (Sidanius \& Pratto, 1999; Pratto, Sidanius, \& Levin, 2006). Such lower social value is inextricably linked to their individual feelings of lower self-concept, self-esteem, self-efficacy, and negative identity development. They may also face exclusion from specific jobs. The effects of GD on deflating self-concepts of females can affect their body-image (and related body-satisfaction/dissatisfaction). Body dissatisfaction in early adolescence found to significantly contribute to the development of gender differences in depressive symptoms and disordered eating across early to mid-adolescence (Ferreiro, Seoane, \& Senra, 2014). Girls outnumber boys with disordered eating by a ratio of 3:1 (Ferreiro, Seoane, \& Senra, 2012). Our current results confirm the effects of GD on disordered eating in the American Indian sample. As the current results confirmed, GD was associated with reduced self-esteem and self-esteem mediated the negative effects of positive appraisal on PTSD and general assessment of functioning (GAF). These findings substantiates the existence of this pathway to negative effects of GD. Pervasive sexism was found to be associated with lower self-esteem (Schmitt, Branscombe, \& Postmes, 2003). Lower levels of self-esteem have been related to greater mental health problems and substance abuse and to lower levels of life satisfaction in early adulthood (Boden, Fergusson, \& Horwood, 2008).

Intersectionality Hypothesis

GD was found to be closely related and interface with other identity related traumas, providing evidence of the Intersectionality perspective (Shields, 2008), and lend evidence of GD proliferation and cumulative dynamics inherent in type III continuous identity traumas (Kira et al. 2013a). Special note is its association, not only with collective identity traumas (e.g., discriminations for race and ethnicities, uprootedness for American Indians and Palestinians), but also with betrayal and personal identity traumas (e.g., sexual abuse, incest, abandonment and domestic violence). This may be related to the findings that females are more affected by betrayal traumas (e.g., Tang, Shin, \& Freyd, 2012) as well other personal identity traumas than males. Many females experience gender-related issues as independent and/or secondary to race, class, age, or religion. Interconnectedness of multiple personal and collective facets of identity is influenced by myriad social statuses and dynamics (Enns, 2010; Shields, 2008).

\section{GD-P and GD-S}

Gender discrimination by parents and family members was generally associated with less dysfunction than gender discrimination by society's institutions which may be logical for adults who are more affected by social institutions than adolescents who may be affected more with GD perpetrated by family members. The exception 
was the results of American Indian (AI) sample in which GD by parents and family members was either equal to or worse than gender discrimination by social institutions, in terms of the actual occurrence and associated severity of impact. AI/NA group lives in relatively less gender discriminating society in the US, while GD by family is still high. Native American women suffer GBV at a rate three and a half times greater than the national average (Bachman et al. 2008). American Indians live in relatively less gender discriminative social culture compared to Egyptian and Palestinians patriarchal cultures. Family culture may have slower change rate than social culture in AI/NA (BigFoot \& Braden, 1998). More studies are needed to assess the differential effects of each (GD-P and GD-S) in different age and cultural groups and explore in detail its dynamics.

Appraisal and Coping of GD

As path analysis indicated in Egyptian sample, negative appraisal coping predicted, no negative effects on mental health, while positive appraisal of GD (a potential marker for internalizing GD) predicted significant increase in mental health markers, mediated by self-esteem (e.g., increased depression, PTSD, and GAF). The results were straightforward, however, we have to caution that appraising GD as negative may not mean active coping through resistance of GD, for example, through feminist ideology. Positive appraisal seems to be a coping strategy that accepts and internalize discrimination to avoid confronting the GD related distressing emotions. Positive appraisal seems to be counter-productive avoidant coping strategy as it predicted negative effects on self-esteem and mental health. What the participants meant by "positive appraisal" could be equivalent with "given-up", which means that "positive" cognitive appraisal is not really "positive" in nature in this case. "Given-up" to oppression is, in substance, a negative coping appraisal and thus related with lowered self-esteem. The results lend to the effects of oppression hypothesis on appraisal. The positivity expected from such positive appraisal, in effective coping with trauma in non-oppressive situations, was nullified or reversed in the context of the oppression involved in GD (compare, e.g., Soto et al., 2012, Perez \& Soto, 2011, Matheson et al., 2007). Reduced distress, resulted from positive appraisal of dysfunctional situation might limit active efforts to alter such situation, and coping strategies that might appear beneficial, when considered in the broader context may actually undermine well-being (Matheson et al., 2007).

Theories and research of intergroup contact may shed some lights on the dynamics of internalizing gender discrimination by the disadvantage gender. Positive intergroup contact (e.g., between the two genders) found to enable the ideological legitimation of inequality perpetuating one's own disadvantage, while in-group contact (contact with the same gender) has opposite effects (Sengupta \& Sibley, 2013). Intergroup contact has sedative effects on disadvantaged-group members' perceptions of intergroup inequality in ways that can undermine their support for social change toward equality (Saguy, Tausch, Dovidio, \& Pratto, 2009). More cross-cultural research need to corroborate and generalize these results.

\section{Implications for Therapy and Counseling}

Feminist therapy emerged as an important psychotherapy framework for GD (e.g., Brown, 2006; Enns \& Byars-Winston, 2010, Worell, \& Remer, 2003). Transforming unequal gender relations and promoting shared power, control of resources, decision-making, and support for women's empowerment is important. Gender mainstreaming and transformation should be a goal for social justice advocacy and counseling for both genders, especially in cultures and families with high level of GD such as AI/NA (e.g., Mann, 2008), and Arab Americans (Kira, Amer, \& Wroble, 2014). Feminist therapy should address the interface of class, culture and gender in counseling (D'Andrea \& Daniels, 2001). Addressing GD and promoting natural equality is likely to help both males and females by restoring self-esteem, reducing the associated chronic internalizing symptoms for affected females; and by decreasing inflated self-worth, related to domination of males with associated externalizing and high risk taking behaviors (Kira et al., 2012a).

Research on the sexual differentiation of the brain, brain organization theory provides considerable and longstanding evidence that early hormonal effects are not permanent and plasticity and epigenetic and cultural factors modulate gender in the human brain (e.g., Jordan-Young, 2010; Kaiser, 2012). Empowering females and promoting gender equality in all social, civil, economic, and teaching institutions, as well as within households and the media, are necessary to address this disparity and change the epigenetics of gender discrimination. Mental health promotion and prevention interventions can be used to address the negative social and health outcomes of gender discrimination. Targeting patriarchal cultures ideologies, using media and globalization dynamics to spread awareness and promote international culture of gender equality is one effective way to address the social determinants of mental health. Cognitive Behavioral approaches that address distorted appraisal strategies in oppression, may be helpful to address disparities and gender discrimination. Working with female clients, vic- 
tims of different forms of GD, for example domestic violence, clinicians can challenge the distorted beliefs about gender inequality, activate discrimination-resisting and survival coping schemas. These interventions will likely help the recovery of identity and the increase of self-worth and level of functioning, which will subsequently lead to better mental health for victims of gender discrimination.

Most current evidence-based approaches are focused on past trauma, and do not address present and continuous type III trauma, such as the case in GD. Utilizing the DBTF framework on GD gives new optics that can help in developing more effective interventions for such continuous and present traumas in males and females. Recent trauma-focused therapeutic models are emerging to address such continuous trauma types (Kira et al., 2012g, 2013a; Kira, 2013; Murray, Cohen, \& Mannarino, 2013; Kira \& Tummala-Narra, 2014). Kira, 2013, proposed a model of six components to address continuous traumatic stress such as in GD. The model includes prioritizing safety and addressing current and ongoing threats and dangers utilizing behavioral skills training. It involves psycho-education on continuous traumatic stress and cumulative and proliferation and stress generation dynamics. It also consists of identity work, identity restoration, group self-esteem and efficacy (e.g., gender selfesteem) and identity development, as well as stimulating "will to survive" and related meaningful effective coping strategies (such as feminist ideology in the case of GD). It also comprises inoculation against stress proliferation and accumulation dynamics, inherent in GD, as well as advocacy. More work that focus on developing and testing effective therapy models to such chronic traumas is greatly needed.

Study Limitations

Current pilot research was exploratory in nature through secondary analysis of data collected in four different studies using two items sub-scale of GD, and its two single items. More detailed targeted studies, using larger measures of GD, are needed to validate the main assumptions of gender discrimination trauma and appraisal theory introduced in this paper. Further, due to the risk of type I error that may ensue in conducting a great number of partial correlation analyses caution is advised in interpreting associations with significance less than .01. Additionally, GD effects could be confounded by the effects of other traumas which may suggest that residual confounding remains a possibility and so we refrain from making conclusive statements about causality.

Conclusion

Regardless of these limitations, current study provides strong evidence of the stable negative effects of GD across different cultures with different intensities of GD. It demonstrates the validity and utility of traumatology perspective in analyzing discriminations as type III continuous trauma. Our results suggest that the affected selfconcept due to such discriminations that deflate self-esteem in victim (i.e., affected female) and inflate it in perpetrator (i.e., dominant males) is a significant contributing factor of such negative effects. Future studies that replicate and analyze discrimination and GD as type III traumas are needed.

\section{References}

Afifi, T. O., MacMillan, H., \& Cox, B. J. (2009). Mental Health Correlates of Intimate Partner Violence in Marital Relationships in a Nationally Representative Sample of Males and Females. Journal o Interpersonal Violence, 24, 1398-1417. http://dx.doi.org/10.1177/0886260508322192

Al Krenawi, A., Graham, J. R., \& Sehwail, M. A. (2007). Tomorrow’s Players under Occupation: An Analysis of the Association of Political Violence with Psychological Functioning and Domestic Violence among Palestinian Youth. American Journal of Orthopsychiatry, 77, 427-433. http://dx.doi.org/10.1037/0002-9432.77.3.427

Altshuler, B. (1981). Modeling of Dose-Response Relationships. Environmental Health Perspectives, 42, $23-27$. http://dx.doi.org/10.1289/ehp.814223

Aronson, J., Quinn, D. M., \& Spencer, S. J. (1998). Stereotype Threat and the Academic Performance of Women and Minorities. In J. K. Swim, \& C. Stangor (Eds.), Prejudice: The Target's Perspective (pp. 83-103). San Diego, CA: Academic Press. http://dx.doi.org/10.1016/B978-012679130-3/50039-9

Ayers, M. M. (2009). Adolescent Girls’ Experiences with Sexism, Racism, and Classism: The Role of Social Support from Parents and Friends. Dissertation Abstracts International: Section B: The Sciences and Engineering, 69, 4457.

Bachman, R., Zaykowski, H., Kallmyer, R., Poteyeva, M., \& Lanier, C. (2008). Violence against American Indian and Alaska Native Women and the Criminal Justice Response: What is Known? Document No.: 223691, Washington DC: Department of Justice.

Bharadwaj, P., \& Nelson, B. K. (2012) Discrimination Begins in the Womb-Evidence of Sex Selective Prenatal Investments. Journal of Human Resources, 48, 71-113.

BigFoot, D. S., \& Braden, J. (1998). On the Back of a Turtle. Oklahoma City: University of Oklahoma Health Sciences Center. 
Blacke, D. D., Weathers, F. W., Nagy, L. M., Kaloupek, D. G., Klauminzer, G., Charney, D. S., \& Keane, T. M. (1990). A Clinician Rating Scale for Assessing Current and Lifetime PTSD: The CAPS-1. Behavior Therapist, 13, 187-188.

Boden, J. M., Fergusson, D. M., \& Horwood, L. J. (2008). Does Adolescent Self-Esteem Predict Later Life Outcomes? A Test of the Causal Role of Self-Esteem. Development and Psychopathology, 20, 319-339. http://dx.doi.org/10.1017/S0954579408000151

Brescoll, V. L., Uhlmann, E. L., \& Newman, G. E. (2013). The Effects of System-Justifying Motives on Endorsement of Essentialist Explanations for Gender Differences. Journal of Personality and Social Psychology, 105, 891-908. http://dx.doi.org/10.1037/a0034701

Brondolo, E., Thompson, S., Brady, N., Appel, R., Cassells, A., Tobin, J. N. et al. (2006). The Relationship of Racism to Appraisals and Coping in a Community Sample. Ethnicity and Disease, 15, 14-19.

Brown, L. S. (2006). Still Subversive after All These Years: The Relevance of Feminist Therapy in the Age of EvidenceBased Practice. Psychology of Women Quarterly, 30, 15-24. http://dx.doi.org/10.1111/j.1471-6402.2006.00258.x

Correa-Velez, I., Gifford, S. M., \& Barnett, A. G. (2010). Longing to Belong: Social Inclusion and Wellbeing among Youth with Refugee Backgrounds in the First Three Years in Melbourne, Australia. Social Science \& Medicine, 71, 1399-1408. http://dx.doi.org/10.1016/j.socscimed.2010.07.018

Crawford, J. R., \& Henry, J. D. (2003). The Depression Anxiety Stress Scales: Normative Data and Latent Structure in a Large Non-Clinical Sample. British Journal of Clinical Psychology, 42, 111-131.

http://dx.doi.org/10.1348/014466503321903544

Crosby, F. (1984). The Denial of Personal Discrimination. American Behavioral Psychologist, 27, 371-386.

D’Andrea, M., \& Daniels, J. (2001). RESPECTFUL Counseling: An Integrative Model for Counselors. In D. Pope-Davis, \& H. Coleman (Eds.), The Interface of Class, Culture and Gender in Counseling (pp. 417-466). Thousand Oaks, CA: Sage.

Daly, K. and Chesney-Lind, M. (1988) Feminism and Criminology. Justice Quarterly, 5, 497-538. http://dx.doi.org/10.1080/07418828800089871

Das Gupta, M., Zhenghua, J., Bohua, L., Zhenming, X., Chung, W., \& Hwa-Ok, B. (2003). Why Is Son Preference So Persistent in East and South Asia? A Cross-Country Study of China, India and the Republic of Korea. Journal of Development Studies, 40, 153-187. http://dx.doi.org/10.1080/00220380412331293807

Diop-Sidibéa, N., Campbellb, J., \& Beckerc, S. (2006). Domestic Violence against Women in Egypt—Wife Beating and Health Outcomes. Social Science \& Medicine, 62, 1260-1277. http://dx.doi.org/10.1016/j.socscimed.2005.07.022

Enns, C. (2010). Locational Feminisms and Feminist Social Identity Analysis. Professional Psychology: Research and Practice, 41, 333-339. http://dx.doi.org/10.1037/a0020260

Enns, C. Z. (2004). Feminist Theories and Feminist Psychotherapies: Origins, Themes, and Diversity (2nd ed.). New York: Haworth.

Enns, C. Z., \& Byars-Winston, A. (2010). Multicultural Feminist Therapy. In H. Landrine, \& N. F. Russo (Eds.), Handbook of Diversity in Feminist Psychology (pp. 367-388). New York: Springer.

Ferreiro, F., Seoane, G., \& Senra, C. (2011). A Prospective Study of Risk Factors for the Development of Depression and Disordered Eating in Adolescents. Journal of Clinical Child and Adolescent Psychology, 40, 500-505. http://dx.doi.org/10.1080/15374416.2011.563465

Ferreiro, F., Seoane, G., \& Senra, C. (2012). Gender-Related Risk and Protective Factors for Depressive Symptoms and Disordered Eating in Adolescence: A 4-Year Longitudinal Study. Journal of Youth and Adolescence, 41, 607-622. http://dx.doi.org/10.1007/s10964-011-9718-7

Ferreiro, F., Seoane, G., \& Senra, C. (2014). Toward Understanding the Role of Body Dissatisfaction in the Gender Differences in Depressive Symptoms and Disordered Eating: A Longitudinal Study during Adolescence. Journal of Adolescence, 37, 73-84. http://dx.doi.org/10.1016/j.adolescence.2013.10.013

Foster, M. (2009). The Dynamic Nature of Coping with Gender Discrimination: Appraisals, Strategies and Well-Being over Time. Sex Roles, 60, 694-707. http://dx.doi.org/10.1007/s11199-008-9568-2

Freyd, J. J., Deprince, A., \& Gleaves, D. (2007). The State of Betrayal Trauma Theory: Reply to McNally-Conceptual Issues and Future Directions. Memory, 15, 295-311. http://dx.doi.org/10.1080/09658210701256514

Garcia, D. M., Schmitt, M., Branscombe, N., \& Ellemers, N. (2010). Women’s Reactions to In-Group Members Who Protest Discriminatory Treatment: The Importance of Beliefs about Inequality and Response Appropriateness. European Journal of Social Psychology, 40, 733-745.

Gillespie, G. L., \& Gates, D. (2013). Using Proactive Coping to Manage the Stress of Trauma Patient Care. Journal of Trauma Nursing, 20, 44-50. http://dx.doi.org/10.1097/JTN.0b013e318286608e

Gormally, J., Black, S., Daston, S., \& Rardin, D. (1982). The Assessment of Binge Eating Severity among Obese Persons. Addictive Behaviors, 7, 47-55. http://dx.doi.org/10.1016/0306-4603(82)90024-7 
Greeno, C. G., Marcus, M. D., \& Wing, R. R. (1995). Diagnosis of Binge Eating Disorder: Discrepancies between a Questionnaire and Clinical Interview. International Journal of Eating Disorders, 17, 153-160.

http://dx.doi.org/10.1002/1098-108X(199503)17:2<153::AID-EAT2260170208>3.0.CO;2-V

Haj-Yahia, M. M. (1998). Beliefs about Wife Beating among Palestinian Women: The Influence of Their Patriarchal Ideology. Violence against Women, 4, 533-558. http://dx.doi.org/10.1177/1077801298004005002

Hank, K. (2007). Parental Gender Preferences and Reproductive Behavior: A Review of the Recent Literature. Journal of Biosocial Sciences, 39, 759-767. http://dx.doi.org/10.1017/S0021932006001787

Head, D., Singh, T., \& Bugg, J. M. (2012). The Moderating Role of Exercise on Stress-Related Effects on the Hippocampus and Memory in Later Adulthood. Neuropsychology, 26, 133-143. http://dx.doi.org/10.1037/a0027108

Heilman, M. E., \& Okimoto, T. G. (2007). Why Are Women Penalized for Success at Male Tasks? The Implied Communality Deficit. Journal of Applied Psychology, 92, 81-92. http://dx.doi.org/10.1037/0021-9010.92.1.81

Hu, L., \& Bentler, P. M. (1999). Cutoff Criteria for Fit Indexes in Covariance Structure Analysis: Conventional versus New Alternatives. Structural Equation Modeling, 6, 1-55. http://dx.doi.org/10.1080/10705519909540118

Jaggar, A. M., \& Rothenberg, P. S. (1993). Feminist Frameworks: Alternative Theoretical Accounts of the Relations between Women and Men (3rd ed.). New York: McGraw-Hill.

Jordan-Young, R. (2010) Brain Storm: The Flaws in the Science of Sex Differences. Cambridge, MA: Harvard University Press.

Jost, J. T., Banaji, M. R., \& Nosek, B. A. (2004). A Decade of System Justification Theory: Accumulated Evidence of Conscious and Unconscious Bolstering of the Status Quo. Political Psychology, 25, 881-919. http://dx.doi.org/10.1111/j.1467-9221.2004.00402.x

Kaiser, A. (2012). Re-Conceptualizing 'Sex’ and ‘Gender' in the Human Brain. Journal of Psychology, 220, 130-136.

Kaiser, C. R. (2007). Dominant Ideology Threat and the Interpersonal Consequences of Attributions to Discrimination. In S. Levin, \& C. van Laar (Eds.), Stigma and Group Inequality (pp. 45-64). Mahwah, NJ: Erlbaum.

Kaufman, J. M. (2009). Gendered Responses to Serious Strain: The Argument for a General Strain Theory of Deviance. Justice Quarterly, 26, 410-444. http://dx.doi.org/10.1080/07418820802427866

Kay, A. C., Gaucher, D., Peach, J. M., Friesen, J., Laurin, K., Zanna, M. P., \& Spencer, S. J. (2009). Inequality, Discrimination, and the Power of the Status Quo: Direct Evidence for a Motivation to View What Is as What Should Be. Journal of Personality and Social Psychology, 97, 421-434. http://dx.doi.org/10.1037/a0015997

Kira, A., Amer, M. M., \& Wrobel, N. H. (2014). Arab Refugees: Trauma, Resilience, and Recovery. In S. C. NassarMcMillan et al. (Eds.), A Biopsychosocial Approach to Arab Americans: Perspectives on Culture, Development, and Health (pp.). New York: Springer.

Kira, I. (2001). Taxonomy of Trauma and Trauma Assessment. Traumatology: An International Journal, 2, 1-14.

Kira, I. (2004). Secondary Trauma in Treating Refugee Survivors of Torture and Their Families. Torture, 14, 38-44.

Kira, I. (2010). Etiology and Treatments of Post-Cumulative Traumatic Stress Disorders in Different Cultures. Traumatology: An International Journal, 16, 128-141.

Kira, I. (2013). Interventions with Continuous Traumatic Stress of Discrimination in Youth. Proceedings of the International Symposium on Arab Youth: Developmental Pathways for Identity, Windsor, 29-30 May 2013. http://scholar.uwindsor.ca/arabyouthsymp/conference_presentations/presentations2/3/

Kira, I. A., Ashby, J. S., Odenat, L., \& Lewandowski, L. (2013). The Mental Health Effects of Torture Trauma and Its Severity: A Replication and Extension. Psychology, 4, 472-482. http://dx.doi.org/10.4236/psych.2013.45067

Kira, I. A., Omidy, A. Z., \& Ashby, J. S. (2014). Cumulative Trauma, Appraisal and Coping in Palestinian and American Indian Adults: Two Cross-Cultural Studies. Traumatology: An International Journal, 20, 119-133. http://dx.doi.org/10.1037/h0099397

Kira, I., \& Tummala-Narra, P. (2014). Psychotherapy with Refugees: Emerging Paradigm. Journal of Loss and Trauma: International Perspectives on Stress \& Coping, 19, 1-19. http://dx.doi.org/10.1080/15325024.2014.949145

Kira, I., Ahmed, A., Wassim, F., McAdams-Mahmoud, V., Clorain, J., \& Rai, D. (2012g). Group Therapy for Refugees and Torture Survivors: Treatment Models Innovations. International Journal of Group Psychotherapy, 62, 63-83.

Kira, I., Alawneh, A. N., Aboumediene, S., Mohanesh, J., Ozkan, B., \& Alamia, H. (2011b). Identity Salience and Its Dynamics in Palestinians Adolescents. Psychology, 2, 781-791. http://dx.doi.org/10.4236/psych.2011.28120

Kira, I., Alawneh, A., Aboumediene, S., Lewandowski, L., \& Laddis, A. (2014). Dynamics of Oppression and Coping from Traumatology Perspective: The Example of Palestinian Youth. Peace and Conflict: Journal of Peace Psychology, 20, 385411. http://dx.doi.org/10.1037/pac0000053

Kira, I., Ashby, J. S., Lewandowski, L., Alawneh, A. N., Mohanesh, J., \& Odenat, L. (2013). Advances in Continuous 
Traumatic Stress Theory: Traumatogenic Dynamics and Consequences of Intergroup Conflict: The Palestinian Adolescents case. Psychology, 4, 396-409. http://dx.doi.org/10.4236/psych.2013.44057

Kira, I., Ashby, J., Lewandowski, L., Smith, I., \& Odenat, L. (2012). Gender Inequality and Its Effects in Females Torture Survivors. Psychology, 3, 352-363. http://dx.doi.org/10.4236/psych.2012.34050

Kira, I., Clifford, D., \& Al-Haider, A. (2003). Assessing and Treating Cumulative Trauma Disorders (CTD) in Iraqi Refugees. Proceedings of the American Psychological Association Annual Convention, Toronto, 7-11 August 2003. http://psycnet.apa.org/index.cfm?fa=search.displayRecord\&id=09025690-DA01-DDCA-09D5-18516337631D\&resultID= 61\&page $=3 \& \mathrm{dbTab}=$ all\&search $=$ true

Kira, I., Fawzi, M., \& Fawzi, M. (2013). The Dynamics of Cumulative Trauma and Trauma Types in Adults Patients with Psychiatric Disorders: Two Cross-Cultural Studies. Traumatology: An International Journal, 19, 179-195.

Kira, I., Lewandowski, L., Chiodo, L., \& Ibrahim, A. (2014). Advances in Systemic Trauma Theory: Traumatogenic Dynamics and Consequences of Backlash as a Multi-Systemic Trauma on Iraqi Refugee Muslim Adolescents. Psychology, 5 , 389-412. http://dx.doi.org/10.4236/psych.2014.55050

Kira, I., Lewandowski, L., Somers, C., Yoon, J., \& Chiodo, L. (2012e) PTSD, Trauma Types, Cumulative Trauma and IQ: The Case of African American and Iraqi Refugee Adolescents. Psychological Trauma: Theory, Research, Practice, and Policy, 4, 128-139. http://dx.doi.org/10.1037/a0022121

Kira, I., Lewandowski, L., Templin, T., Ramaswamy, V., Ozkan, B., \& Mohanesh, J. (2008). Measuring Cumulative Trauma Dose, Types and Profiles Using a Development-Based Taxonomy of Trauma. Traumatology: An International Journal, 14, 62-87.

Kira, I., Smith, I., Lewandowski, L., \& Templin, T. (2010). The Effects of Perceived Gender Discrimination on Refugee Torture Survivors: A Cross-Cultural Traumatology Perspective. Journal of the American Psychiatric Nurses Association, 16, 299-306. http://dx.doi.org/10.1177/1078390310384401

Kira, I., Templin, T., Lewandowski, L., Ashby, J. S., Oladele, A., \& Odenat, L. (2012). Cumulative Trauma Disorder Scale: Two Studies. Psychology, 3, 643-656. http://dx.doi.org/10.4236/psych.2012.39099

Kira, I., Templin, T., Lewandowski, L., Clifford, D., Wiencek, E., Hammad, A., Al-Haidar, A., \& Mohanesh, J. (2006). The Effects of Torture: Two Community Studies. Peace and Conflict: Journal of Peace Psychology, 12, 205-228. http://dx.doi.org/10.1207/s15327949pac1203_1

Kira, I., Templin, T., Lewandowski, L., Ramaswamy, V., Bulent, O., Mohanesh, J., \& Abdulkhaleq, H. (2012f). Collective and Personal Annihilation Anxiety: Measuring Annihilation Anxiety AA. Psychology, 3, 90-99. http://dx.doi.org/10.4236/psych.2012.31015

Kira, I., Templin, T., Lewandowski, L., Ramaswamy, V., Bulent, O., Abu-Mediene, S., Mohanesh, J., \& Alamia, H. (2011a). Cumulative Tertiary Appraisal of Traumatic Events Across Cultures: Two Studies. Journal of Loss and Trauma: International Perspectives on Stress \& Coping, 16, 43-66. http://dx.doi.org/10.1080/15325024.2010.519288

Kline, R. B. (2005). Principles and Practice of Structural Equation Modeling (2nd ed.). New York: The Guilford Press.

Krieger, N. (1999). Embodying Inequality: A Review of Concepts, Measures, and Methods for Studying Health Consequences of Discrimination. International Journal of Health Services, 29, 295-352. http://dx.doi.org/10.2190/M11W-VWXE-KQM9-G97Q

Krug, G., Dahlberg, L., Mercy, J., Zwi, A., \& Lozano, R. (Eds.) (2002). World Report on Violence and Health. Geneva: World Health Organization.

Kunda, Z. (1990). The Case for Motivated Reasoning. Psychological Bulletin, 108, 480-498. http://dx.doi.org/10.1037/0033-2909.108.3.480

Landrine, H., Klonoff, E. A., Gibbs, J., Manning, V., \& Lund, M. (1995). Physical and Psychiatric Correlates of Gender Discrimination. Psychology of Women Quarterly, 19, 473-492. http://dx.doi.org/10.1111/j.1471-6402.1995.tb00087.x

Larsen, J. T., Norris, C. J., McGraw, A. P., Hawkley, L. C., \& Cacioppo, J. T. (2009). The Evaluative Space Grid: A Single Item Measure of Positivity and Negativity. Cognition and Emotion, 23, 453-480.

http://dx.doi.org/10.1080/02699930801994054

London, B., Downey, G., Romero-Canyas, R., Rattan, A., \& Tyson, D. (2012). Gender-Based Rejection Sensitivity and Academic Self-Silencing in Women. Journal of Personality and Social Psychology, 102, 961-979. http://dx.doi.org/10.1037/a0026615

Lovibond, P. F., \& Lovibond, S. H. (1995). The Structure of Negative Emotional States: Comparison of the Depression Anxiety and Stress Scales (DASS) with the Beck Depression and Anxiety Inventories. Behavior Research and Therapy, 33, 335-342. http://dx.doi.org/10.1016/0005-7967(94)00075-U

Mann, B. A. (2008). Make a Beautiful Way: The Wisdom of Native American Women. Lincoln, NE: University of Nebraska Press. 
Matheson, K., Skomorovsky, A., Fiocco, A., \& Anisman, H. (2007). The Limits of 'Adaptive’ Coping: Well-Being and Mood Reactions to Stressors among Women in Abusive Dating Relationships. Stress, 10, 75-91. http://dx.doi.org/10.1080/10253890701208313

McHorney, C. A., Ware Jr., J. E., \& Raczek, A. E. (1993) The MOS 36-Item Short-Form Health Survey (SF-36): II. Psychometric and Clinical Tests of Validity in Measuring Physical and Mental Health Constructs. Medical Care, 31, $247-263$. http://dx.doi.org/10.1097/00005650-199303000-00006

Millender, E. I. (2013). Cumulative Trauma among Adult Mayas Living in Southeast Florida. Ph.D. Dissertation, Boca Raton, FL: Florida Atlantic University, 196 p.

Murray, L. K., Cohen, J. A., \& Mannarino, A. P. (2013). Trauma-Focused Cognitive Behavioral Therapy for Youth Who Experience Continuous Traumatic Exposure? Peace and Conflict: Journal of Peace Psychology, 19, 180-195. http://dx.doi.org/10.1037/a0032533

Narayan, U. (1997). Dislocating Cultures. Identities, Traditions and Third World Feminism. London: Routledge.

Omidy, A. Z. (2012). Influence of Cumulative Trauma, Binge Eating, and Coping Styles on the General Health of American Indians. Ph.D. Dissertation, Norman, OK: University of Oklahoma.

Palestinian Central Bureau for Statistics (PCBS) (2006). Domestic Violence Survey (December 2005-January 2006) Main Findings. Ramallah: PCBS.

Pascoe, E. A., \& Richman, S. L. (2009). Perceived Discrimination and Health: A Meta-Analytic Review. Psychological Bulletin, 135, 531-554. http://dx.doi.org/10.1037/a0016059

Perez, C. R., \& Soto, J. A. (2011). Cognitive Reappraisal in the Context of Oppression: Implications for Psychological Functioning. Emotion, 11, 675-680. http://dx.doi.org/10.1037/a0016059

Pico-Alfonso, M., Garcia-Linares, M., \& Celda-Navarro, N. (2006). The Impact of Physical, Psychological, and Sexual Intimate Male Partner Violence on Women's Mental Health: Depressive Symptoms, Posttraumatic Stress Disorder, State Anxiety, and Suicide. Journal of Women's Health, 15, 599-611. http://dx.doi.org/10.1089/jwh.2006.15.599

Pratto, F., Sidanius, J., \& Levin, S. (2006). Social Dominance Theory and the Dynamics of Intergroup Relations: Taking Stock and Looking Forward. European Review of Social Psychology, 17, 271-320. http://dx.doi.org/10.1080/10463280601055772

Purdie-Vaughns, V., Steele, C. M., Davies, P., Ditlmann, R., \& Crosby, J. R. (2008). Social Identity Contingencies: How Diversity Cues Signal Threat or Safety for African-Americans in Mainstream Settings. Journal of Personality and Social Psychology, 94, 615-630. http://dx.doi.org/10.1037/0022-3514.94.4.615

Radloff, L. S. (1977). The CES-D Scale: A Self-Report Depression Scale for Research in the General Population. Applied Psychological Measurement, 1, 385-401. http://dx.doi.org/10.1177/014662167700100306

Rafferty, Y. (2008). The Impact of Trafficking on Children: Psychological and Social Policy Perspectives. Child Development Perspectives, 2, 13-18. http://dx.doi.org/10.1111/j.1750-8606.2008.00035.x

Rees, S., Silove, D., Chey, T., Ivancic, L., Steel, Z., \& Creamer, M. (2011). Lifetime Prevalence of Gender-Based Violence in Women and the Relationship with Mental Disorders and Psychosocial Function. JAMA, 306, 513-521.

Rosenberg, M. (1965). Society and the Adolescent Self-Image. Princeton, NJ: Princeton University Press.

Rosenfield, S., Lennon, M. C., \& White, H. R. (2005). The Self and Mental Health: Self-Salience and the Emergence of Internalizing and Externalizing Problems. Journal of Health and Social Behavior, 46, 323-340. http://dx.doi.org/10.1177/002214650504600402

Saguy, T., Tausch, N., Dovidio, J. F., \& Pratto, F. (2009). The Irony of Harmony: Intergroup Contact Can Produce False Expectations for Equality. Psychological Science, 20, 114-121. http://dx.doi.org/10.1111/j.1467-9280.2008.02261.x

Scherer, K. R., Shorr, A., \& Johnstone, T. (Eds.) (2001). Appraisal Processes in Emotion: Theory, Methods, Research. Canary, NC: Oxford University Press.

Schmitt, M. T., Branscombe, N. R., \& Postmes, T. (2003). Women's Emotional Responses to the Pervasiveness of Gender Discrimination. European Journal of Social Psychology, 33, 297-312. http://dx.doi.org/10.1002/ejsp.147

Sengupta, N. K., \& Sibley, C. G. (2013). Perpetuating One’s Own Disadvantage: Intergroup Contact Enables the Ideological Legitimation of Inequality. Personality and Social Psychology Bulletin, 39, 1391-1403. http://dx.doi.org/10.1177/0146167213497593

Shah, M. (2005). Son Preference and Its Consequences (A Review). Gender \& Behavior, 3, 269-280.

Shields, S. A. (2008). Gender: An Intersectionality Perspective. Sex Roles, 59, 301-311. http://dx.doi.org/10.1007/s11199-008-9501-8

Sidanius, J., \& Pratto, F. (1999). Social Dominance: An Intergroup Theory of Social Hierarchy and Oppression. New York: Cambridge University Press. http://dx.doi.org/10.1017/CBO9781139175043 
Soto, J. A., Armenta, B. E., Perez, C. R., Zamboanga, B. L., Umaña-Taylor, A. J., Lee, R. M., Schwartz, S. J., Park, I. J. K., Huynh, Q., Whitbourne, S. K., Le, T. N., \& Ham, L. S. (2012). Strength in Numbers? Cognitive Reappraisal Tendencies and Psychological Functioning among Latinos in the Context of Oppression. Cultural Diversity and Ethnic Minority Psychology, 18, 384-394. http://dx.doi.org/10.1037/a0029781

Steele, C. M., Spencer, S., \& Aronson, J. (2002). Contending with Group Image: The Psychology of Stereotype and Social Identity Threat. In M. Zanna (Ed.), Advances in Experimental Social Psychology (Vol. 37). Waltham: Academic Press.

Sullivan, T. P. (2012) Is It the Exception or the Rule? Daily Co-Occurrence of Physical, Sexual, and Psychological Partner Violence in a 90-Day Study of Substance-Using, Community Women. Psychology of Violence, 2, 154-164. http://dx.doi.org/10.1037/a0027106

Szymanski, D. M., \& Gupta, A. (2009). Examining the Relationship between Multiple Internalized Oppressions and African American Lesbian, Gay, and Bisexual Persons' Self-Esteem and Psychological Distress. Journal of Counseling Psychology, 56, 110-118. http://dx.doi.org/10.1037/a0013317

Tang, S., Shin, S., \& Freyd, J. J. (2012). Betrayal Trauma and Gender Differences in Posttraumatic Stress. Psychological Trauma: Theory, Research, Practice, and Policy, 4, 469-478. http://dx.doi.org/10.1037/a0025765

United Nations Human Development Program (2013). Gender Inequality Index (GII). https://data.undp.org/dataset/Table-4-Gender-Inequality-Index/pq34-nwq7

Walter, J. (2001). Refugees and Domestic Violence: Model-Building as a Prelude to Services Research. Journal of Social Work Research, 2, 237-249.

Wanous, J., \& Hudy, M. J. (2001). Single-Item Reliability: A Replication and Extension. Organizational Research Methods, 4, 361-375. http://dx.doi.org/10.1177/109442810144003

Ware, J. E., \& Sherbourne, C. D. (1992). The MOS 36-Item Short-Form Health Survey (SF-36): Conceptual Framework and Item Selection. Medical Care, 30, 473-483. http://dx.doi.org/10.1097/00005650-199206000-00002

Watts, C., \& Zimmerman, C. (2002). Violence against Women: Global Scope and Magnitude. The Lancet, 359, $1232-1237$. http://dx.doi.org/10.1016/S0140-6736(02)08221-1

Weathers, F., Keane, T., \& Davidson, J. (2001). The Clinician-Administered PTSD Scale: A Review of the First Ten Years of Research. Depression and Anxiety, 13, 132-156. http://dx.doi.org/10.1002/da.1029

Wood, W., \& Eagley, A. H. (2003). A Cross-Cultural Analysis of the Behavior of Women and Men: Implications for the Origins of Sex Differences. Psychological Bulletin, 128, 699-727. http://dx.doi.org/10.1037/0033-2909.128.5.699

Woodcock, A., Hernandez, P., Estrada, M., \& Schultz, P. W. (2012). The Consequences of Chronic Stereotype Threat: Domain Disidentification and Abandonment. Journal of Personality and Social Psychology, 103, 635-646. http://dx.doi.org/10.1037/a0029120

Yeung, A. W. Y., Kay, A. C., \& Peach, J. M. (2014). Anti-Feminist Backlash: The Role of System Justification in the Rejection of Feminism. Group Processes and Intergroup Relations, 17, 474-484. http://dx.doi.org/10.1177/1368430213514121 
Scientific Research Publishing (SCIRP) is one of the largest Open Access journal publishers. It is currently publishing more than 200 open access, online, peer-reviewed journals covering a wide range of academic disciplines. SCIRP serves the worldwide academic communities and contributes to the progress and application of science with its publication.

Other selected journals from SCIRP are listed as below. Submit your manuscript to us via either submit@scirp.org or Online Submission Portal.
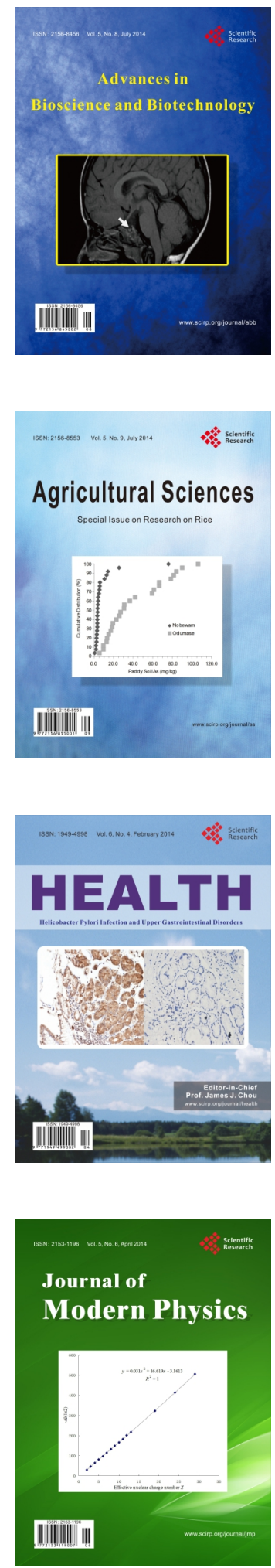
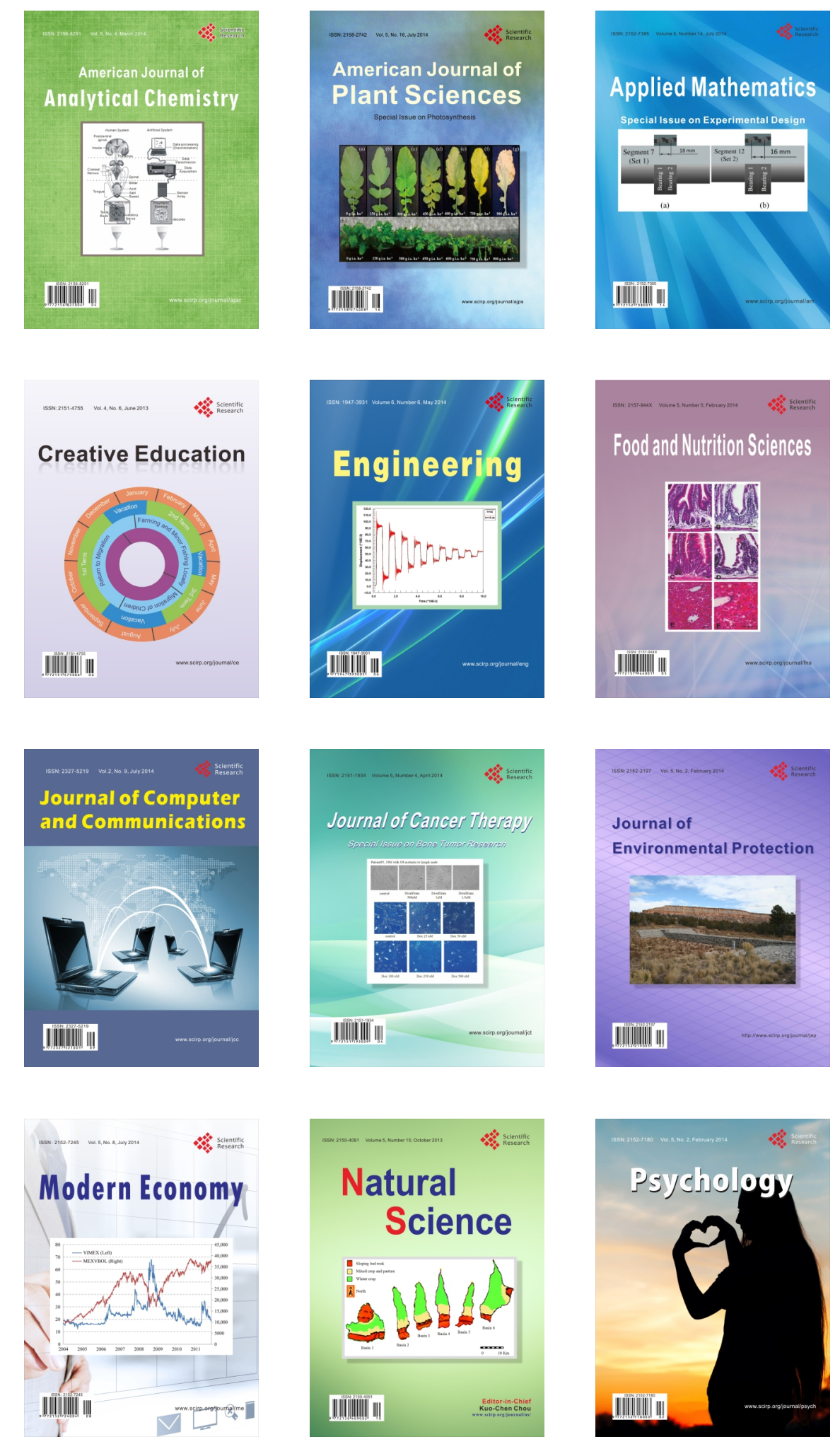